Article

\title{
Soluble Sugar and Lipid Readjustments in the Yarrowia lipolytica Yeast at Various Temperatures and $\mathrm{pH}$
}

\author{
Varvara Yu Sekova ${ }^{1, *}$, Daria I. Dergacheva ${ }^{1}$, Elena P. Isakova ${ }^{1, *}$, Natalya N. Gessler ${ }^{1}$, \\ Vera M. Tereshina ${ }^{2}$ and Yulia I. Deryabina ${ }^{1}$ \\ 1 A.N. Bach Institute of Biochemistry, Russian Academy of Sciences, bld 33-2, Leninsly Prospect, \\ Moscow 119071, Russia; ddarya1993@gmail.com (D.I.D.); gessler51@mail.ru (N.N.G.); \\ yul_der@mail.ru (Y.I.D.) \\ 2 Winogradsky Institute of Microbiology, Research Center of Biotechnology of the Russian Academy of \\ Sciences, Leninsky Ave. 33/2, Moscow 119071, Russia; v.m.tereshina@inbox.ru \\ * Correspondence: beauveria606@gmail.com (V.Y.S.); elen_iss@mail.ru (E.P.I.)
}

Received: 25 November 2019; Accepted: 15 December 2019; Published: 17 December 2019

\begin{abstract}
Microorganisms cope with a wide range of environmental challenges using different mechanisms. Their ability to prosper at extreme ambient $\mathrm{pH}$ and high temperatures has been well reported, but the adaptation mechanism often remains unrevealed. In this study, we addressed the dynamics of lipid and sugar profiles upon different cultivation conditions. The results showed that the cells grown at various $\mathrm{pH}$ and optimal temperature contained mannitol as the major cytosol sugar alcohol. The elevated temperature of $38^{\circ} \mathrm{C}$ led to a two- to three-fold increase in total cytosol sugars with concurrent substitution of mannitol for trehalose. Lipid composition in the cells at optimal temperature changed insignificantly at any $\mathrm{pH}$ tested. The increase in the temperature caused some drop in the storage and membrane lipid levels, remarkable changes in their composition, and the degree of unsaturated fatty acids. It was shown that the fatty acid composition of some membrane phospholipids varied considerably at changing $\mathrm{pH}$ and temperature values. The data showed a pivotal role and flexibility of the sugar and lipid composition of Y. lipolytica W29 in adaptation to unfavorable environmental conditions.
\end{abstract}

Keywords: thermal shock; ambient pH; yeast; metabolic readjustments; lipids; carbohydrates

\section{Introduction}

The Yarrowia lipolytica yeast is capable of adapting to various environmental challenges. The microorganism can prosper at extremely high (up to 9.5) and low (up to 2.5) [1] ambient pH [2], as well as under conditions of high salinity using either dry or hydrophobic substrates [3]. Alkaline tolerance is not common among the yeast species since their optimal growth $\mathrm{pH}$ is usually within the range 5.0-6.5, and the yeast can rarely resist alkaline stress of above $\mathrm{pH}$ 8.0. The $Y$. lipolytica yeast has been widely used for producing lipase, organic acids, and some recombinant proteins [4,5]. The ability of Y. lipolytica to utilize low-cost substrates of various compositions (petroleum waxes, crude biomass hydrolysates, and industrial waste) and to yield a large amount of biomass renders the yeast species a most prospective one for biotechnological use.

The ability of living organisms to survive under stress is usually associated with changes in gene expression, resulting in some readjustments at the molecular and biochemical levels. External effects, such as temperature, ambient $\mathrm{pH}$, and salinity, greatly influence the growth and development of a yeast cell. The adaptation response to changes in medium temperature and salinity besides adaptive synthesis of stress proteins includes the altered content of membrane lipids, accumulation of some 
cytosol carbohydrates, and cytoprotectant molecules [6]. The osmolytic system is known to be an essential defense factor against various harmful effects. The carbohydrate composition in fungal cells changes depending on the culture growth phase and physiological state. Thus, environmental challenges, such as thermal or osmotic shocks, and oxidative stress can promote either accumulation or consumption of certain carbohydrates, namely non-reducing disaccharide trehalose and two polyols, glycerol and D-arabitol, in a cell [7].

There is a group of carbohydrate compounds, such as disaccharide trehalose, glycosyl-glycerol, and some polyols (glycerol, erythritol, arabitol, mannitol, inositol, sorbitol), which protect microorganisms against various stresses. These metabolites can stabilize macromolecules and cell membranes under the conditions of water shortage, osmotic shock, and both high and low temperatures [8,9]. A number of the compounds in the cells can perform osmo-protective and thermo-stabilizing functions [10]. In Candida albicans, an osmotic shock of $1 \mathrm{M}$ sodium chloride induced a minor decrease in trehalose and $D$-arabitol contents. However, oxidative exposure by the oxidants promoted a significant rise in both trehalose and $D$-arabitol levels [10]. Under cold and osmotic stresses, the Aspergillus niger fungus showed the excretion of glycerol, D-arabitol, and erythritol into the medium [11]. A high erythritol level was also observed in Y. lipolityca at extremely low $\mathrm{pH}(\mathrm{pH}$ 3.0) [12]. Some soluble cytosol carbohydrates function as direct antioxidants on cellular structures and macromolecules. Thus, mannitol, widely known as an reactive oxygen species (ROS) scavenger, is capable of protecting animal and plant pathogens against ROS generated by the host organism during the anti-stress response $[13,14]$. The participation of mannitol in the antioxidant defense response of a fungal cell has also been reported for plant pathogens of Alternaria alternata [15] and Uromyces fabae [16].

Natural disaccharide trehalose, which acts as a universal signaling and protective agent in a fungal cell as a protein and phospholipid stabilizer in the membrane lipid bilayer, also appeared to be a powerful antioxidant. So, $S$. cerevisiae demonstrated that increases in trehalose levels led to a higher survival during mild heat shock $\left(38^{\circ} \mathrm{C}\right)$, after the ROS-generating system $\left(2 \mathrm{mM} \mathrm{H}_{2} \mathrm{O}_{2}\right.$ and $1 \mathrm{mM} \mathrm{FeCl}_{3}$ at $28^{\circ} \mathrm{C}$ ) was exposed, and administration of the proteasome inhibitor (MG132) to the medium [17]. Similar results were published in the paper [18] concerning the study of metabolic rearrangement in $S$. cerevisiae under prolonged heat exposure $\left(8 \mathrm{~h}\right.$ at $\left.37^{\circ} \mathrm{C}\right)$. The authors observed a jump in the trehalose content after 0.5 and $2 \mathrm{~h}$ of thermal exposure, with further stabilization of the disaccharide level. Moreover, the tps1 and tps2 mutants of $S$. cerevisiae, unable to synthesize trehalose, were much more sensitive to ROS effects than the wild type, which indicates the high antioxidant role of trehalose in a yeast cell [19]. Cell membranes, as a defense barrier of a cell, alter their lipid composition in response to various kinds of stress. Alkaliphilic micromycete of Sodiomyces tronii contain more sterols and sphingolipids in the membrane lipids at acidic ambient $\mathrm{pH}$ [20]. Non-optimum $\mathrm{pH}$ invoked significant changes in the degree of fatty acid unsaturation, amount of the sterols, and phosphatidylcholine (PC) fractions in the membrane lipids in alkaliphilic Sodiomyces magadii and alkalinus, as well as alkali-tolerant Acrostalagmus luteoalbus and Chordomyces antarcticus [20].

Moreover, the intrinsic flexibility of the eukaryotic lipidome depending on growth conditions, such as temperature and growth phase, was shown using Saccharomyces cerevisiae [21]. Ethanol stress in the $S$. cerevisiae yeast led to some changes in membrane structure and lipid composition [22]. Some other factors, namely, carbon source, can impact considerably on the lipid composition and degree of unsaturation of the fatty acids [23]. Some recent studies have assayed the influence of sterol composition on the survival of $S$. cerevisiae at various stresses. Hence, the survival of the mutant in $\operatorname{erg} 6 \Delta$, unable to synthesize ergosterol, remarkably dropped after osmotic shock [24]. Some osmolytes, in particular, trehalose, play an essential role in protecting fatty acids against free radical oxidation. They can prevent the dehydration of unsaturated linoleic and linolenic acids, resulting in aldehyde formation and inhibition of the auto-oxidation of unsaturated fatty acids, leading to peroxide formation. It all together indicates a direct interaction of trehalose with acyl chains and stabilization of fatty acid structures [8]. Inositol also plays a significant role in cell protection, being a precursor of phosphatidylinositol (PI), which, in turn, is the source for such necessary signaling and structural 
molecules as phosphoinositides, inositol polyphosphate [25], and inositol-containing sphingolipids (SL) [26]. Moreover, some genes of glycerophospholipid synthesis maximally express when no inositol is in the growth medium, and repress when inositol is added to that [27].

The content and composition of lipids and fatty acids in the Y. lipolytica cells significantly depends on the growth conditions and the type of substrate used. In studies of the lipid and fatty acid composition using Y. lipolytica Po1 $g$ grown on various substrates (in defatted rice hydrolyzate, the cells could accumulate up to $81.5 \%$ of neutral free fatty acids, $6.12 \%$ of monoacylglycerides (MAGs), $5.32 \%$ of triglycerides (TAGs), and only $4.87 \%$ of diacylglycerides (DAGs). The dominating free fatty acid were oleic (C18:0, 55.55\%), palmitic (C16:0, 17.76\%), palmitoleic (C16: 1, 14.62\%), and stearic (C18:0, $4.39 \%)$ acids. However, long-chain fatty acids ( $<\mathrm{C} 18: 0)$ made up only $8.27 \%$ of the fatty acids [28].

Genetic manipulations help to change the lipid composition in Y. lipolytica cells. Thus, the commercial production of $\omega-3$ oils using $Y$. lipolytica yeast has high industrial capacity, which has prompted researchers to modify the synthesis of some long-chain polyunsaturated fatty acids using genetic engineering. Some long-chain fatty acids, namely eicosapentaenoic (EPA, C20:5 n-3) and docosahexaenoic acids (DHAs, C22:6 n-3), are used for medical purposes for patients with diseases of the cardiovascular system and hypertriglyceridemia [28]. This acid plays an important role in the treatment of some diseases, like cancer prevention, antiatherogenic effects, and so on. The $Y$. lipolytica yeast grown on soybean as a substrate reached a conjugated linoleic acid (CLA) yield of $3.1 \mathrm{~g} / \mathrm{L}$ (16\% dry weight), as well as $0.9 \mathrm{~g} / \mathrm{L}$ of release into the culture medium [28].

Changes in the cultivation conditions cause a complex readjustment of the fatty acid composition in yeast cell and the degree of unsaturation. Thus, the application of $\mathrm{Se}^{4+}(20 \mathrm{mg} / \mathrm{L})$ into the culture medium increased the unsaturated fatty acid level, especially oleic (C18:1), linoleic (C18:2), linolenic (C18:3), and palmitoleic (C16:1) acids in Candida utilis [29]. Moreover, the authors showed an increase in the margaric (C17:0), heptadecenoic (C17:1), and tetradecanoic (C14:1) acid levels. In these conditions, the increase in the unsaturated fatty acids share in the lipid profile in the yeast cell was related to an increase in desaturase activity, which increased the cell membranes fluidity in the yeast [29]. Some changes in the growth conditions and especially temperature shifts could determine the fatty acids composition in yeast cell, because the fatty acids alter the membrane fluidity [30]. In [31], a three-fold increase in $\alpha$-linolenic acid production under low-temperature cultivation in the Y. lipolytica line with transformed $\Delta 12-15$ desaturase (RkD12-15) was shown. So far, some studies have used low temperature cultivation in some yeast species, namely $Y$. lipolytica and Mortierella alpina, to produce polyunsaturated fatty acids [32,33]. When cultivated at $28^{\circ} \mathrm{C}$ for $24 \mathrm{~h}$ followed by $20^{\circ} \mathrm{C}$, Y. lipolytica could increase $\gamma$-linolenic acid production by $60.9 \%$ [32]. The elevating temperature increased the long-chain fatty acid levels in Y. lipolytica yeast. This led to the disappearance of short-chain fatty acids like capric acid (C10:0) [28]. Therefore, the cultivation conditions can help to control fatty acids synthesis in yeast cells.

The presented changes in the carbohydrate and lipid profiles in a fungal cell under various stresses and their mutual interaction suggest that these compounds should play a vital role in the adaptation mechanism of the yeast. In this regard, in the present study, we show the adaptive metabolic remodeling of the Y. lipolytica yeast under different $\mathrm{pH}$ and temperatures values.

\section{Results}

\subsection{Growth of the Y. lipolytica Yeast under Different Conditions}

The yeast was grown at various ambient $\mathrm{pH}$ values. Results demonstrate the maximal linear growth at pH 5.5 and no growth at pH below 3.0 (Figure 1A) and above 10.5 (data not shown). Figure $1 \mathrm{~A}$ shows the dependence of the cultivation $\mathrm{pH}$ at the optimal temperature on the growth rate of Y. lipolytica. The optimum $\mathrm{pH}$ of the yeast growth proved to be within 4.5 and 6.0. The growth at ambient $\mathrm{pH}$ ranged from 3.5 to 4.5 and showed a smooth rise on the curve, followed by a slight jump at $\mathrm{pH} 5.0$ and a gradual decrease in the growth rate at $\mathrm{pH} 10.5$ to 11.0. We chose two values for further 
experiments: 5.5 and 9.0. Besides, we cultivated the Y. lipolytica yeast at different temperatures from 20 to $40{ }^{\circ} \mathrm{C}$ with a step of two degrees. At the optimal $\mathrm{pH}$ of 5.5, the yeast grows well in a wide range of temperatures from 20 to $40{ }^{\circ} \mathrm{C}$, showing maximal growth at $29^{\circ} \mathrm{C}$ (Figure 1B). Y. lipolytica does not grow at a temperature above $40^{\circ} \mathrm{C}$. At temperatures of 38 to $40{ }^{\circ} \mathrm{C}$, the growth rate significantly decreased, and the temperature above $40^{\circ} \mathrm{C}$ blocked the growth (data not shown). Increasing the $\mathrm{pH}$ to 9.0 in the optimal temperature resulted in a more extended log-phase to $40 \mathrm{~h}$ and some decrease in growth. The effect of the combined influence led to a significant (about 40\%) decline in the yield biomass compared to that under the optimal conditions (Figure 1C).

To evaluate the physiological state of the Y. lipolytica cells under stress, we assayed the key antioxidant enzymes, namely superoxide dismutases (SODs) and catalases (CATs), in different growth conditions, including the stress ones. The results are presented in Table 1. Increasing the $\mathrm{pH}$ led to a 5.8-fold rise in SODs activities, whereas the elevated temperature increased 12.2-fold. Under the combined stress, those activities increased by 10 times (Table 1). The CATs activity changed insignificantly at increasing ambient $\mathrm{pH}$ and dramatically rose by some orders at both thermal and combined stress (Table 1).

Table 1. Redox state of Y. lipolytica yeast cells.

\begin{tabular}{ccccc}
\hline $\begin{array}{c}\text { Antioxidant } \\
\text { Compound }\end{array}$ & $\mathbf{p H ~ 5 . 5 ; 2 9}{ }^{\circ} \mathbf{C}$ & $\mathbf{p H ~ 9 . 0 ; 2 9}{ }^{\circ} \mathbf{C}$ & $\begin{array}{c}\text { Growth Conditions } \\
\mathbf{p H ~ 5 . 5 ; ~ 3 8 ~}{ }^{\circ} \mathbf{C}\end{array}$ & $\mathbf{p H ~ 9 . 0 ; 3 8}{ }^{\circ} \mathbf{C}$ \\
\hline SODs $^{*}$ & $141 \pm 11 \mathrm{a}$ & $831 \pm 48 \mathrm{a}$ & $1725.48 \pm 63 \mathrm{a}$ & $1407.13 \pm 55 \mathrm{a}$ \\
$\mathrm{CATs}^{* *}$ & $26.58 \pm 5.67 \mathrm{~b}$ & $21.7 \pm 1.78$ & $2.33 \times 10^{7} \pm 1.12 \times 10^{6} \mathrm{~b}$ & $4.59 \times 10^{5} \pm 2.59 \times 10^{4} \mathrm{~b}$ \\
[GSH] $^{\dagger}$ & $15.22 \pm 1.31 \mathrm{c}, \mathrm{d}$ & $8.68 \pm 0.75 \mathrm{c}$ & $54.90 \pm 4.22 \mathrm{~d}$ & $23.30 \pm 3.15$ \\
[GSSG] $^{\ddagger}$ & $3.62 \pm 0.25 \mathrm{e}, \mathrm{f}$ & $4.15 \pm 0.56$ & $36.70 \pm 4.01 \mathrm{e}$ & $11.39 \pm 1.32 \mathrm{f}$ \\
[GSSG]/[GSH] & $\sim 0.24$ & $\sim 0.48$ & $\sim 0.67$ & $\sim 0.48$ \\
\hline
\end{tabular}

* Values are mean \pm SEM (unit of enzymatic activity of SOD per $1 \mathrm{mg}$ of protein) from 5 to 6 independent experiments; ** Values are mean \pm SEM (total CATs activity are $\mu$ mols $\mathrm{H}_{2} \mathrm{O}_{2}$ per $1 \mathrm{mg}$ of protein) from 5 to 6 independent experiments. ${ }^{\dagger}$ Values are mean \pm SEM (total GSH content in $\mu \mathrm{M} / \mathrm{mg} w / w$ ) from 5 to 6 independent experiments. $\ddagger$ Values are mean \pm SEM (total GSSG content in $\mu \mathrm{M} / \mathrm{mg} w / w$ ) from 5 to 6 independent experiments. $\mathrm{a}-p<0.01$; $\mathrm{b}-p<0.0004 ; \mathrm{c}-p<0.03 ; \mathrm{d}-p<0.003 ; \mathrm{e}-p<0.004 ; \mathrm{f}-p<0.001$.

The assay of the reduced and oxidized glutathione level showed that increasing the $\mathrm{pH}$ halved the GSH content while the GSSG level remained unchanged (Table 1). However, the elevated temperature increased the GSH level three-fold and the GSSG level 10-fold. The redox potential of HSSG/GSH increased up to 0.48 at alkaline $\mathrm{pH}$ and 0.67 at the elevated temperature compared to 0.24 under the optimal conditions (Table 1). However, the ratio of the reduced glutathione to the oxidized one decreased more than two-fold. The obtained data indicate the development of the anti-stress response by the Y. lipolytica yeast under these conditions. Thus, we established a few parameters for the growth of the yeast: $\mathrm{pH} 5.5,29^{\circ} \mathrm{C}$. The ability of the $Y$. lipolytica to grow at different $\mathrm{pH}$ and above-optimal temperatures renders the species a convenient model for studying lipid and sugar contents in response to various $\mathrm{pH}$ and temperature values.

\subsection{Cell Viability and Vitality Assays}

The survival assessment by the spotting test as well as the quantitative assay of live, dead, and budding Y. lipolytica cells grown under various conditions showed that the viability of yeast cells changed insignificantly in all the versions and remained at a rather high level within $75 \%$ and $95 \%$ (Figure 1D). The number of budding cells made up, on average, 20\% of the total number. Potentiometric staining of cells with Rhod 123 demonstrated a high degree of yeast mitochondria energization under both optimal (Figure 1E) and stress conditions, namely the elevated temperature (Figure 1F) and combined stress (Figure 1G). It should be noted that the cell shape and size depend on the cultivation conditions. When grown at the elevated temperature and combined stress, the cell decreased in size by $15 \%$ and $50 \%$, respectively.

These results indicate a high energy status of yeast cells under all the conditions tested. 

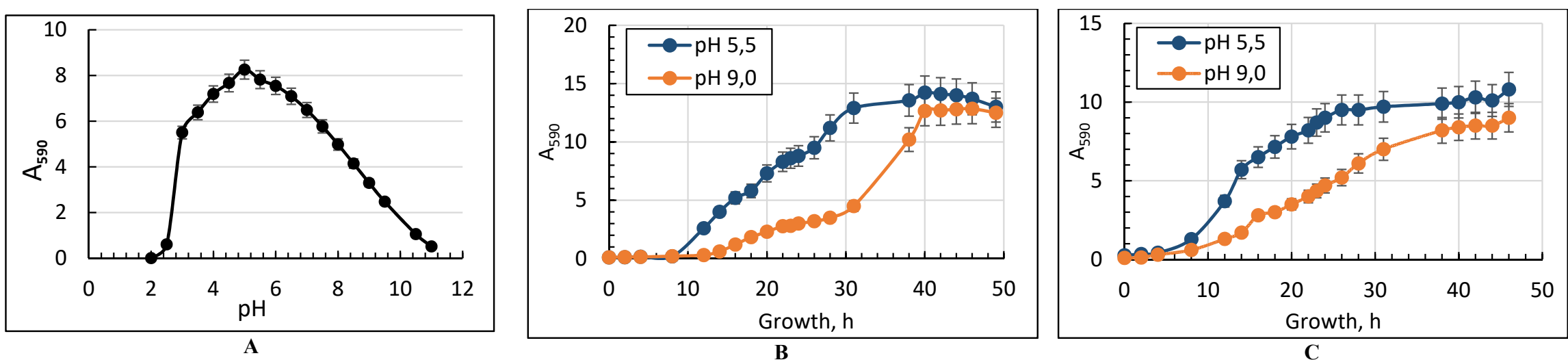

$10^{-5}$

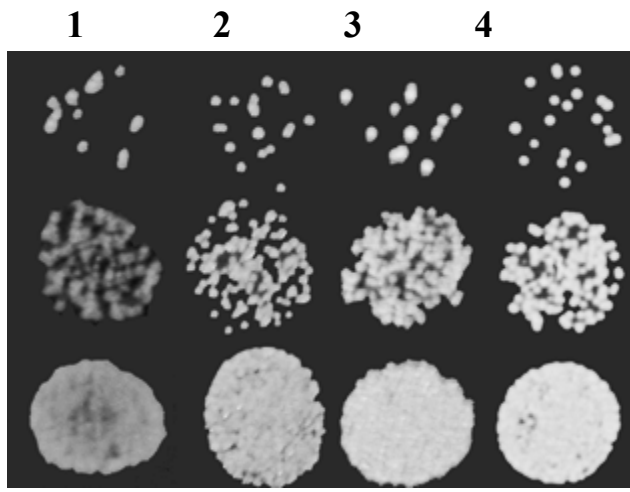

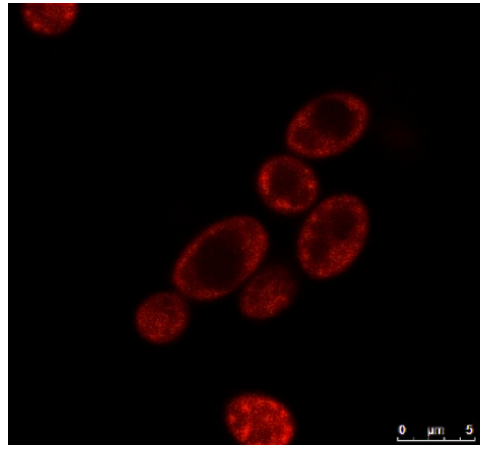

E

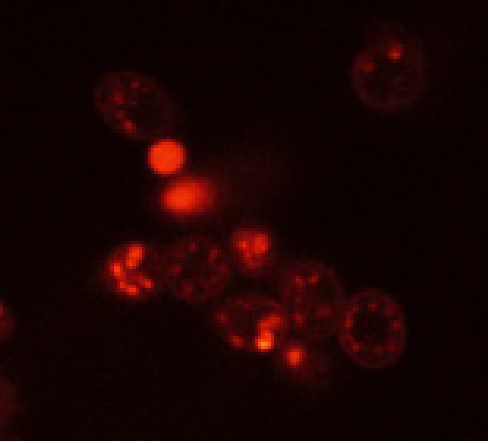

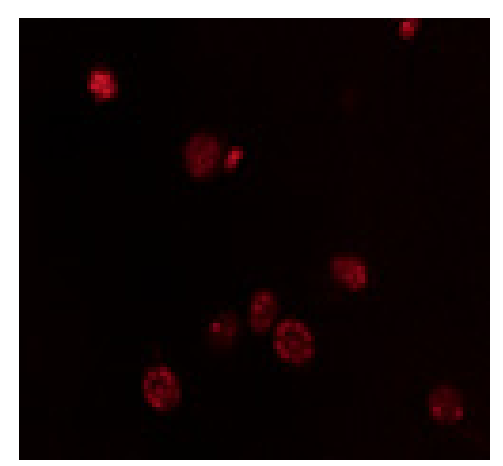

G

Figure 1. The effect of ambient $\mathrm{pH}$ (panel A) on the growth of Yarrowia lipolytica W29 in glycerol-containing (1\%) medium. Panels B,C-Growth curves of the Y. lipolytica yeast grown at $29^{\circ} \mathrm{C}$ (panel B) and at $38^{\circ} \mathrm{C}$ (panel C) in glycerol-containing medium. Absorbance was assessed every two hours in cell suspension at the wavelength of $590 \mathrm{~nm}\left(\mathrm{~A}_{590}\right)$ using a spectrophotometer. Error bars represent the standard deviation of triplicates. Mean values are displayed $(n=3, \pm \mathrm{SD})$. Panel (D)-Spot dilution assays in yeast peptone dextrose (YPD) medium (10 $\mu \mathrm{L}$ per spot). Yeast cells were spotting on corresponding positions of different plates by serial dilutions: $1-\mathrm{pH} 5.5 ; 29^{\circ} \mathrm{C} ; 2-\mathrm{pH} 9.0 ; 29^{\circ} \mathrm{C} ; 3-\mathrm{pH} 5.5 ; 38^{\circ} \mathrm{C} ; 4-\mathrm{pH} 9.0 ; 38^{\circ} \mathrm{C}$. The plates were incubated at $29^{\circ} \mathrm{C}$ for $48 \mathrm{~h}$. Panels (E-G)-micro images of the potential-dependent stain of the $Y$. lipolytica cells with rhodamine $123(\mathrm{Rh} 123)$. $(\mathbf{E})-\mathrm{pH} 5.5 ; 29^{\circ} \mathrm{C} ;(\mathbf{F})-\mathrm{pH} 5.5 ; 38{ }^{\circ} \mathrm{C} ;(\mathbf{G})-\mathrm{pH} 9.0 ; 38^{\circ} \mathrm{C}$. The cells were incubated with $0.5 \mu \mathrm{M}$ Rh123 and examined after $30 \mathrm{~min}$. Incubation medium contained $0.01 \mathrm{M}$ phosphate buffer saline (PBS) and 1\% glycerol, $\mathrm{pH} 7.4$. The regions of high mitochondrial polarization are bright red due to the concentrated dye. To examine the Rh123-stained preparations, filters, 02, 15 (Zeiss), were used (magnification $\times 100)$. The photos were taken using an AxioCam MRC camera. 


\subsection{Cytosolic Soluble Carbohydrate Analysis}

The changes in the cytosolic sugar composition and content can serve as the defense response to stress. So, next, we tracked the composition of sugars and lipids under various culture conditions. Thus, under optimal growth conditions $\left(\mathrm{pH} 5.5 ; 29^{\circ} \mathrm{C}\right)$, the sugar content made up nearly $5 \%$ of the dry weight in the Y. lipolytica cytosol (Figure 2E). A pH increase to 9.0 (Figure 2E) declined the sugar amount by $25 \%$. At the optimal temperature, mannitol was dominating and reached $87 \%$ to $89 \%$ of the total cytosol carbohydrates at any $\mathrm{pH}$ tested (Figure 2A,C). D-arabitol, inositol, and glucose, as the minority, exceeded no more than $6 \%$ of the total amount. Moreover, any changes in ambient $\mathrm{pH}$ caused no sharp fluctuations in the cytosolic sugar composition. A pH increase to 9.0 led to a rise in the arabitol fraction (by 20\%) while the glucose level decreased nearly four-fold (Figure 2C). Neither the growth substrate of glycerol used nor the "stress" sugar of trehalose was revealed in the repertoire of the identified carbohydrates in the yeast cytosol.

An increase in cultivation temperature caused the most remarkable changes in cytosol sugars. Unlike the optimal conditions ( $\mathrm{pH} 5.5 ; 29^{\circ} \mathrm{C}$ ), the elevated temperature and especially, the combined stress (alkaline $\mathrm{pH}(\mathrm{pH} 9.0)$ and elevated temperature $\left(38^{\circ} \mathrm{C}\right)$ caused a significant more than twice, increase in the total sugar content (Figure 2D,E), including a 10-fold increase in the arabitol fraction. Some glycerol amount (of about $5 \%$ of the total sugar content) was observed (Figure 2D). In the cells grown at $38{ }^{\circ} \mathrm{C}$, trehalose reached $65 \%$ to $70 \%$, and $D$-arabitol $20 \%$ to $25 \%$, dominating among the carbohydrates, while mannitol disappeared and the minor carbohydrates (Figure 2B,D) went down even more.
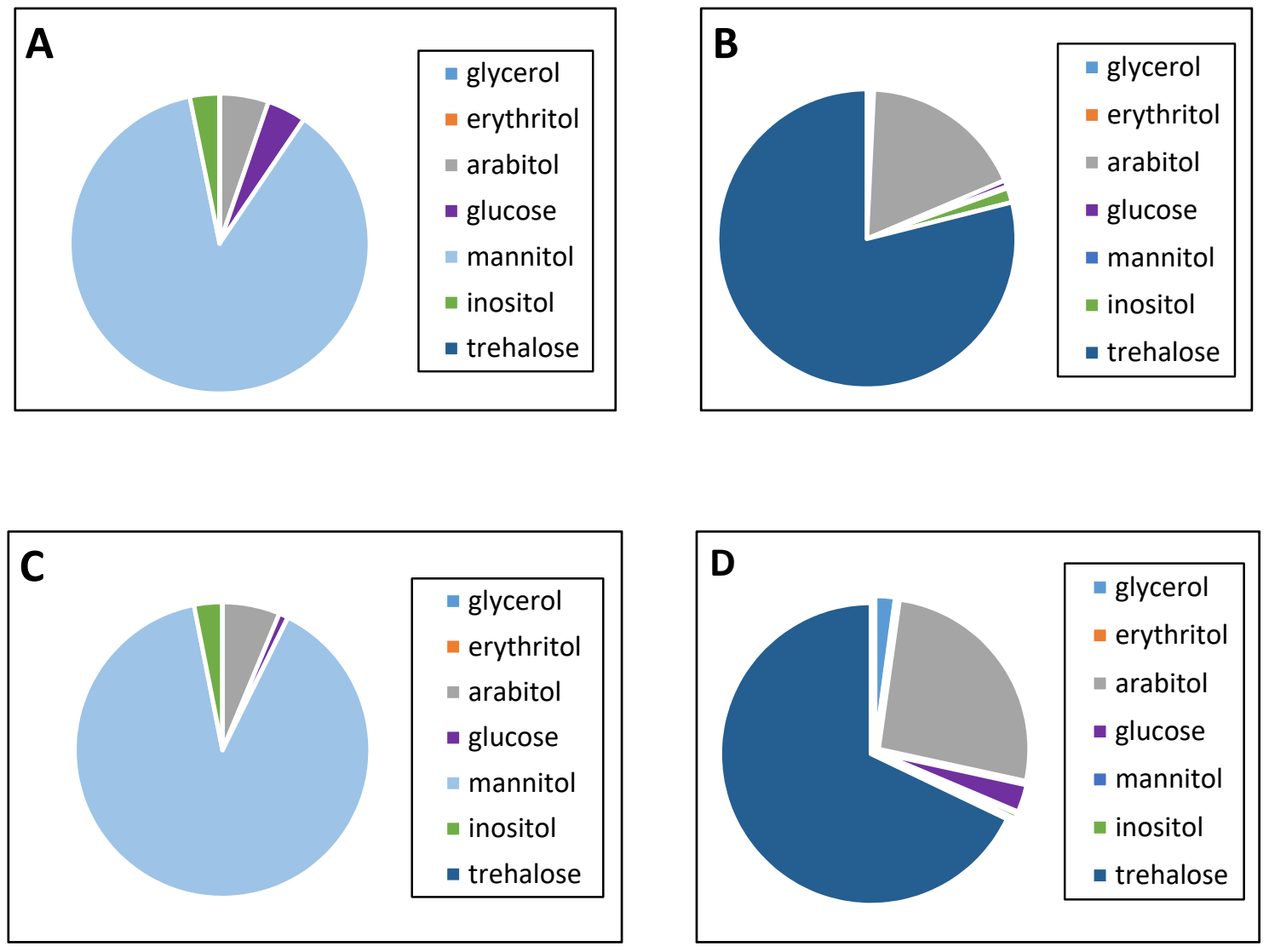

Figure 2. Cont. 


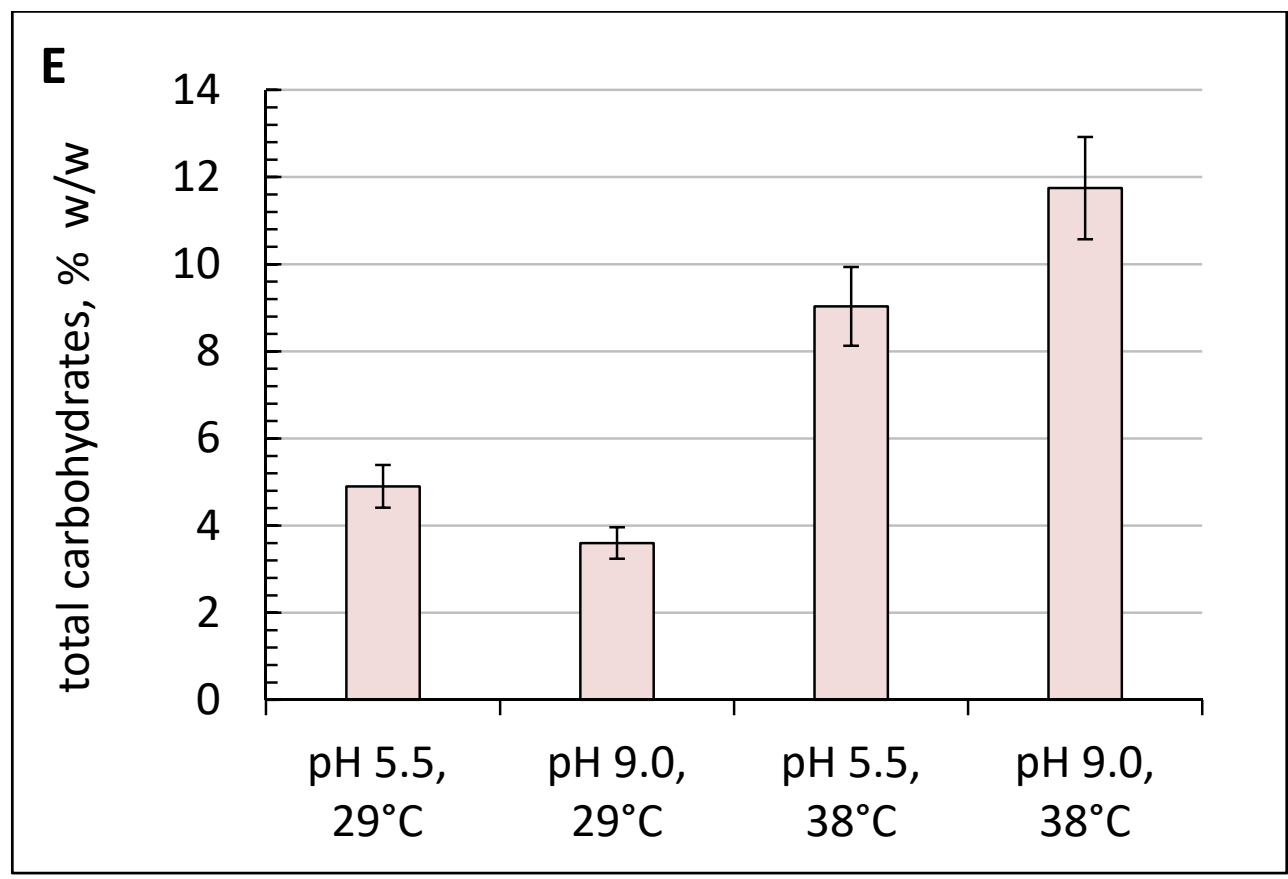

Figure 2. The cytosol sugar and polyol composition in the $Y$. lipolytica yeast grown under different conditions. The share of each soluble cytosolic sugar fraction: (A) $-\mathrm{pH} 5.5,29^{\circ} \mathrm{C}$; (B) $-\mathrm{pH} 5.5,38{ }^{\circ} \mathrm{C}$; (C) - $\mathrm{pH} 9.0,29^{\circ} \mathrm{C}$; (D) - $\mathrm{pH} 9.0,38^{\circ} \mathrm{C}$. (E) - total carbohydrates and polyols content. Error bars represent the standard deviation of triplicates. Mean values are displayed $(n=3, \pm \mathrm{SD})$. $\mathrm{a}-p<0.05$; $\mathrm{b}-p<0.03$.

\subsection{Membrane and Storage Lipids Profile at Various Ambient $p H$ and Temperatures}

In some recent studies, the influence of growth conditions, including carbon source on storage lipid composition, was shown [34]. At the optimal growth temperature, storage lipids were mainly comprised of TAG and FFA in equal amounts (Figure $3 \mathrm{~A}$ ), and the changes in ambient $\mathrm{pH}$ did not affect their ratio. The storage lipid level decreased by a third at $\mathrm{pH} 9.0$ (by 27\%) (Figure 3B). The increase in the growth temperature to $38{ }^{\circ} \mathrm{C}$ declined the total storage lipids content by $35 \%$ (Figure 3B), and the FFA fraction decreased by 4.8 and 1.9 times at $\mathrm{pH} 5.5$ and 9.0, respectively (Figure 3A). In the lipid profiles at $\mathrm{pH} 5.5$, DAG (18\%) appeared, which reached $31.5 \%$ of the total storage lipids at $\mathrm{pH} 9.0$ (Figure 3A). At $\mathrm{pH} 5.5$, the TAG level reached 63\% (Figure 3A) while a $\mathrm{pH}$ increase to 9.0 declined to $37 \%$ of the total storage lipid (Figure $3 \mathrm{~A}$ ). At any $\mathrm{pH}$, the thermal shock led to the appearance of some sterol esters (ESt) in the storage lipids (Figure 3A). The results were confirmed by the ultra-structural features of the yeast cells grown under stress conditions (Figure 3C-F). The largest amount of the storage lipids as lipid bodies (LB) was revealed in the optimal conditions (Figure 3C), decreasing under the stress ones (Figure 3D-F). Under any kind of stress, in the cells, there were some lipid bodies associated with the nucleus. Under the thermal shock, the structure was associated with mitochondria located around lipid bodies, forming the complex of "lipid bodies + nucleus + mitochondria". It could indicate an active migration of lipids between the organelles, maintaining the energy cell state under stress (Figure 3D-F). 

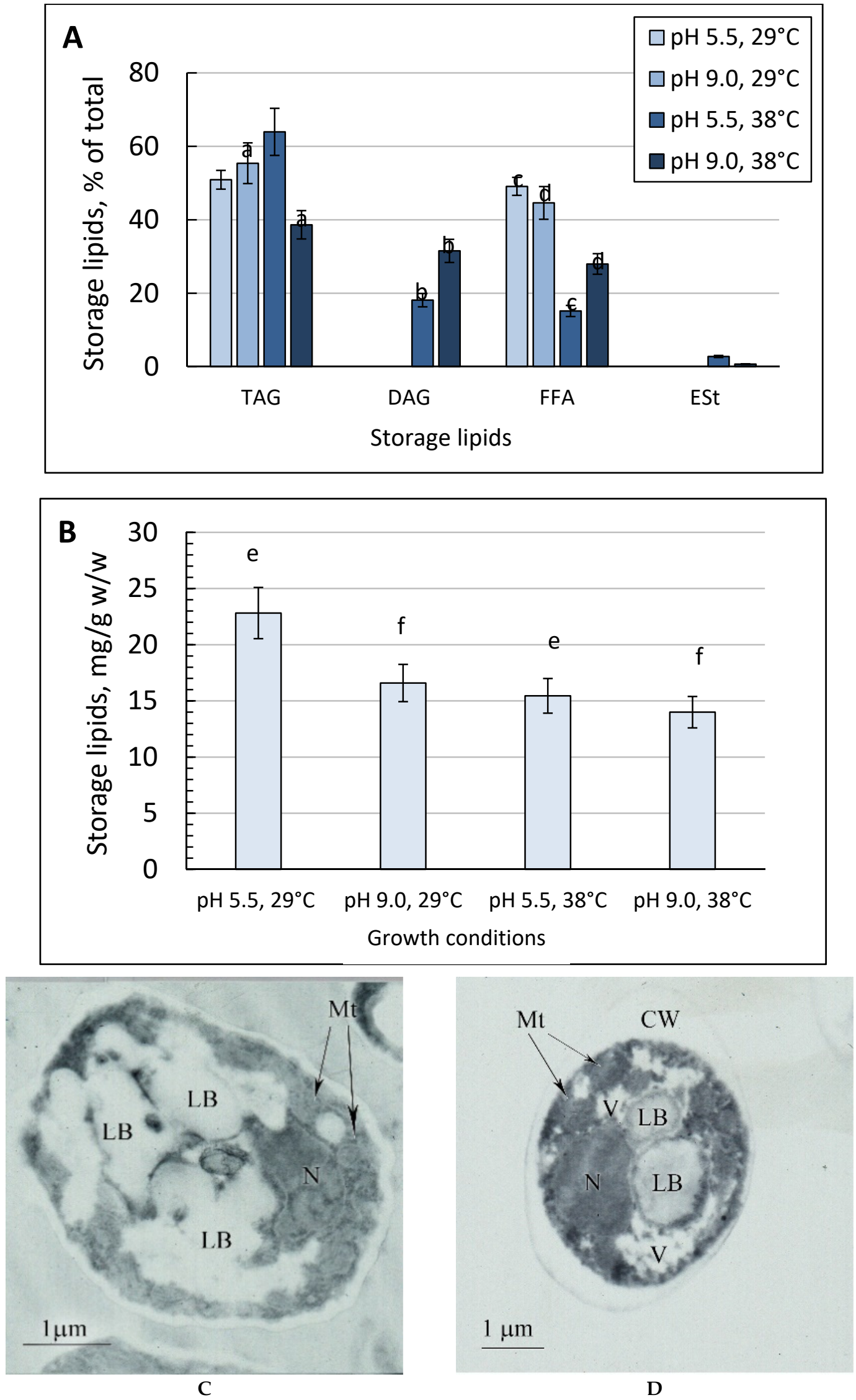

Figure 3. Cont. 


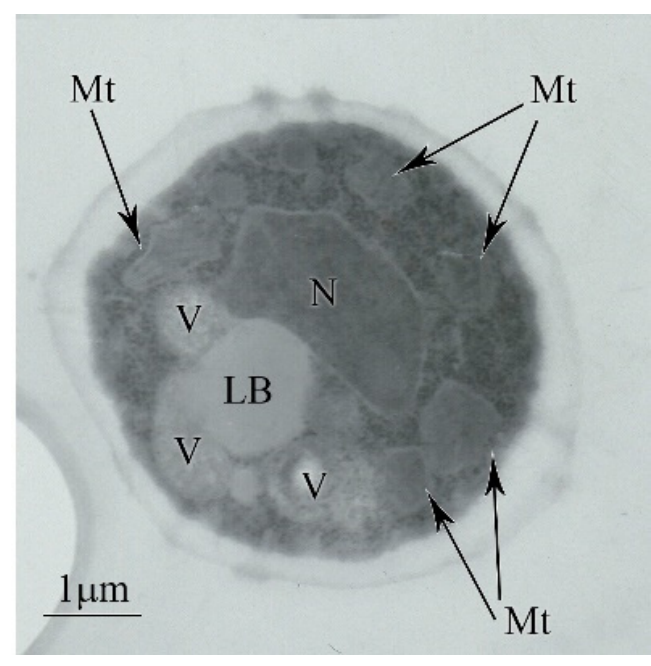

E

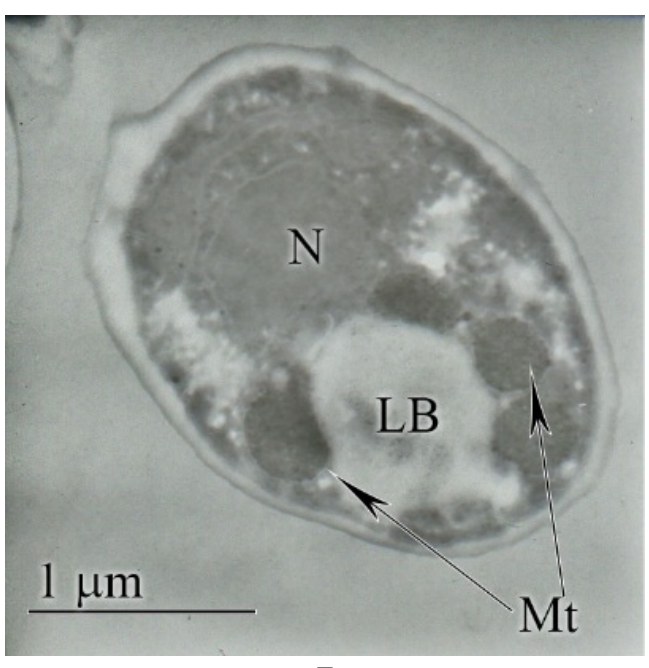

$\mathbf{F}$

Figure 3. The storage lipid composition in the Y. lipolytica yeast grown under different conditions. (A) - the share of each storage lipid fraction, \%; (B)-the total storage lipids content, $\mathrm{mg} / \mathrm{g}$ $w / w$. TAG-Triacylglycerols; DAG-Diacylglycerols; FFA-Free fatty acids; ESt-sterol esters. Error bars represent the standard deviation of triplicates. Mean values are displayed $(n=3, \pm S D)$. (C-F)-Transmission electron microscopy of $Y$. lipolytica $\mathrm{W} 29$ cells grown under various conditions: (C)-pH 5.5, $29{ }^{\circ} \mathrm{C}$; (D)- $\mathrm{pH} 9.0,29{ }^{\circ} \mathrm{C}$; (E)- $\mathrm{pH} \mathrm{5.5,} 38{ }^{\circ} \mathrm{C}$; (F)-pH 9.0, $38{ }^{\circ} \mathrm{C}$; CW-cell wall; LB-lipid body; Mt-mitochondria; $\mathrm{N}-$ nucleus; $\mathrm{V}-$ vacuole. $\mathrm{a}-p<0.04 ; \mathrm{b}-p<0.01 ; \mathrm{c}-p<0.001$; $\mathrm{d}, \mathrm{e}-p<0.02 ; \mathrm{f}-p<0.002$.

The membrane lipid amount reached its peak of $12.98 \mathrm{mg} / \mathrm{g}$ dry weight under the optimal conditions (Figure 4B). Elevating $\mathrm{pH}$ at the optimal growth temperature led to some decrease in the membrane lipid content by $36 \%$ (Figure 4B). The membrane lipid composition of the culture grown at $29^{\circ} \mathrm{C}$ was the same at both $\mathrm{pH}$ values tested. In the membranes, phospholipids (about $50 \%$ ) and sterols (St, $45 \%$ ) dominated, with a minority of SL. The main phospholipids were phosphatidylethanolamine (PE, 16-20\%), phosphotidylcholine (PC, 15\%), and cardiolipin (CL, 7-9\%) (Figure 4A). Phosphatidic acids (PA) varied from $5 \%$ at $\mathrm{pH} 5.5$ to $9 \%$ at $\mathrm{pH} 9.0$ (Figure $4 \mathrm{~A}$ ). The minority comprised lysophosphatidylethanolamines (LPE), lysophosphatidylcholines (LPC), and phosphatidylinosites (PI).

A temperature increase to $38{ }^{\circ} \mathrm{C}$ resulted in nearly a $30 \%$ decrease in the total membrane lipids (Figure 4B) partly due to the more than three-fold decrease in the St level (from $45 \%$ to $11 \%$ ). However, the PE fraction remained at the same level while the PC and PA fractions were 2.0 to 2.5 times increased (Figure 4A). The minority remained constant except for the SL fraction, which was 2.6 times more at the elevated temperature and optimal $\mathrm{pH}$ (Figure $4 \mathrm{~A}$ ).

The combined stress caused the most significant changes in both the amount and composition of membrane lipids, resulting in more than a 3-fold and 1.5-fold increase in the PC and PA fractions, respectively, with a concurrent decrease in the CL fraction (by $40 \%$ ) and St (up to 19\%) (Figure 4A). 

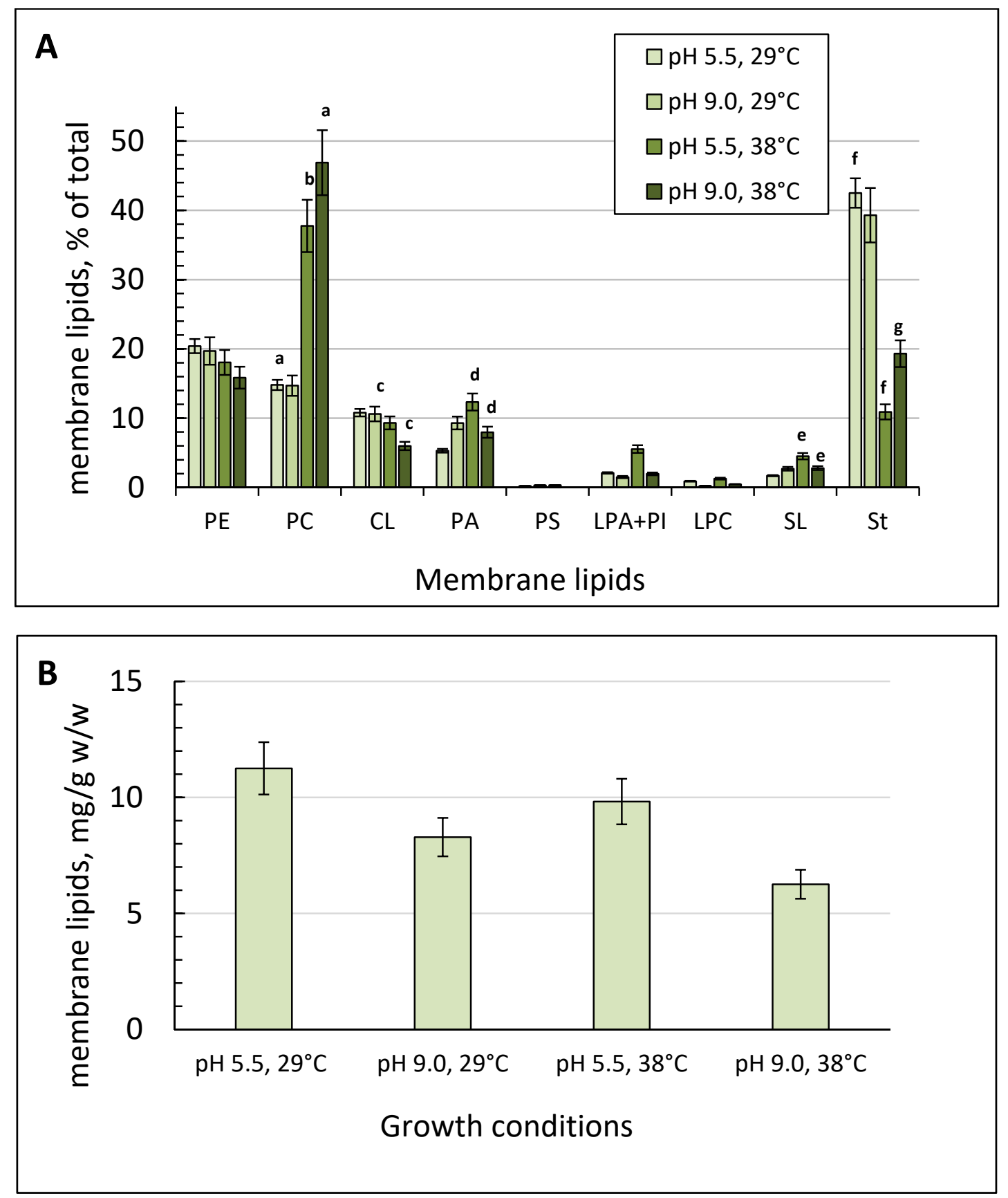

Figure 4. Membrane lipid composition of Y. lipolytica under different conditions. (A) - the share of each membrane lipid fraction, \%; (B) - the total membrane lipid content $\mathrm{mg} / \mathrm{g}$. PE-Phosphatidylethanolamines; PC—Phosphatidylcholines; CL-Cardiolipins; PA-Phosphatidic acids; LPA + PI-lysophosphatidylethanolamine + Phosphatidylinositols; LPC-Lysophosphatidylcholines; SL-Sphingolipids; St-Sterols. The conditions of the culture growth are indicated in the panels. Error bars represent the standard deviation of triplicates. Mean values are displayed $(n=3, \pm \mathrm{SD})$. a $-p$ $<0.01 ; \mathrm{b}, \mathrm{e}, \mathrm{f}-p<0.02 ; \mathrm{c}-p<0.03 ; \mathrm{d}, \mathrm{g}-p<0.05$. 


\subsection{Fatty Acids of the Main Phospholipids under Various Conditions}

The degree of unsaturation of acyl residues in phospholipids determines the fluidity of the membrane lipid bilayer, which in turn may influence the yeast survival and adaptation to alkaline and thermal stresses. Thus, we chromatographically isolated four major PL, the share of which comprised more than $6 \%$, and analyzed their fatty acid composition (Figure 5). Dominating fatty acids in the main membrane PL were stearic (C18:0), oleic (C18:1), and linoleic (C18:2) ones. The PE fraction with an index of hydrogen deficiency (IHD) of 1.5 contained a lot of oleic (C18:1 n9 c) and linoleic (C18:2) acids. Under various conditions, the overall degree of acyl residue unsaturation (IHD) changed due to the alterations in the unsaturation of some membrane PL. Of note, the $\mathrm{pH}$ increase to 9.0 led to some (1.3 times) decreases in the fatty acid IHD of cardiolipin (CL) and phosphatidic acid (PA) fractions (Figure 5B). In the PE fraction, there was a rather high level of saturated fatty acids, namely palmitic (C16:0) (6-12\%) acids. Noteworthy, growth of the culture at $38{ }^{\circ} \mathrm{C}$ and optimal pH resulted in a dramatic disappearance of myristic (C14:0) acid, which appeared again in the PC, CL, and PC fractions at alkaline $\mathrm{pH}$ and the elevated temperature (Figure 5C,D). The most significant changes occurred in the fatty acid composition of the CL fraction. At $\mathrm{pH} 9.0$, the margaric acid content reached $14 \%$ compared to that under optimal conditions, where it was not detected.

Growth of the yeast at $38^{\circ} \mathrm{C}$ was also accompanied by a decrease in the IHD of fatty acids in the membrane lipids (Figure 5E), which was mainly due to a decrease in the linoleic acid content and an increase in the oleic acid one. It should also be noted that at the elevated temperature, all the major membrane phospholipids contained margaric (C17:0) and heptadecenoic (C17:1) acids, which are usually absent in the lipid profile under optimal conditions ( $\mathrm{pH} 5.5 ; 29^{\circ} \mathrm{C}$ ). Moreover, thermal shock provoked an increase in the stearic acid (C18:0) in the main membrane phospholipids, and a significant decrease or disappearance in the short-chain (C13-C15) fatty acids level in the membrane lipids (Figure 5B,D).

The combined stress caused a complete readjustment in the fatty acid composition of the dominant membrane phospholipids (Figure 5E). Besides the abundant margaric (C17:0) and heptadecenoic (C17:1) acids in the cultures grown at the elevated temperature at both $\mathrm{pH}$ tested, the main changes in the fatty acid repertoire concerned the ratio of C18-unsaturated fatty acids (Figure 5D,E). Unlike the Y. lipolytica yeast grown at optimal $\mathrm{pH}$ and elevated temperature, in the cells under combined stress, there was a significant increase in the linoleic (C18:2) acid content in the PE and PC fractions.

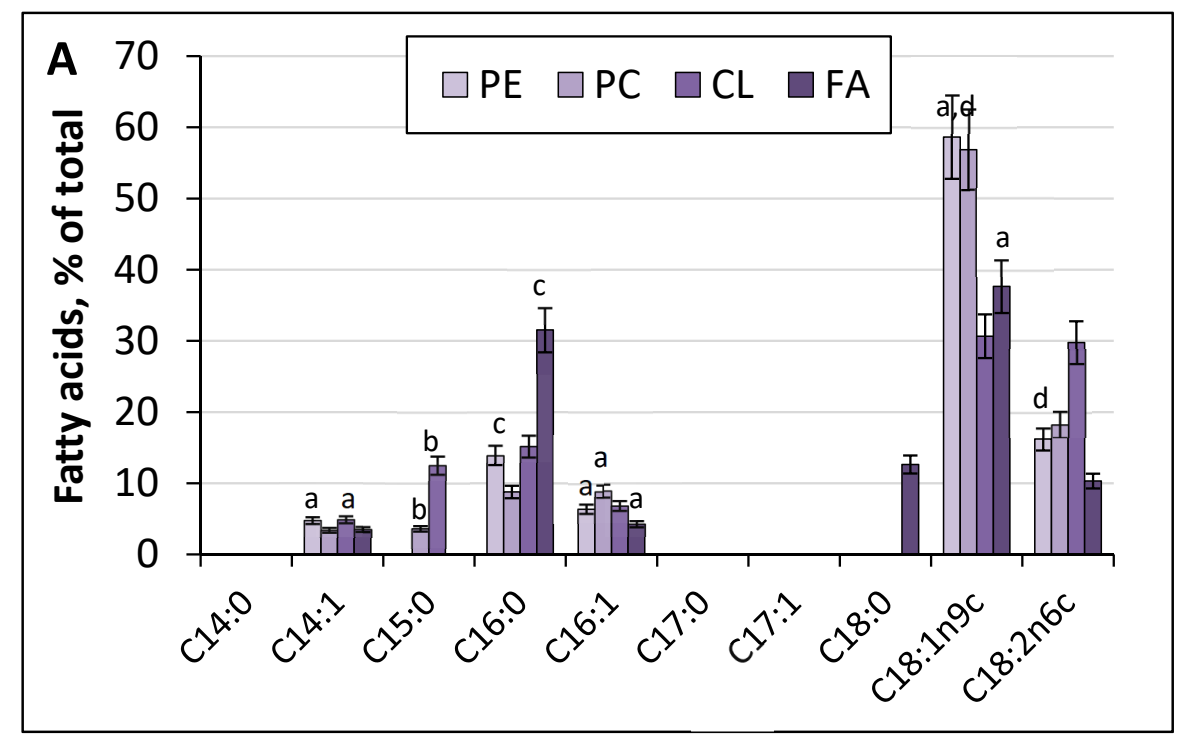

Figure 5. Cont. 

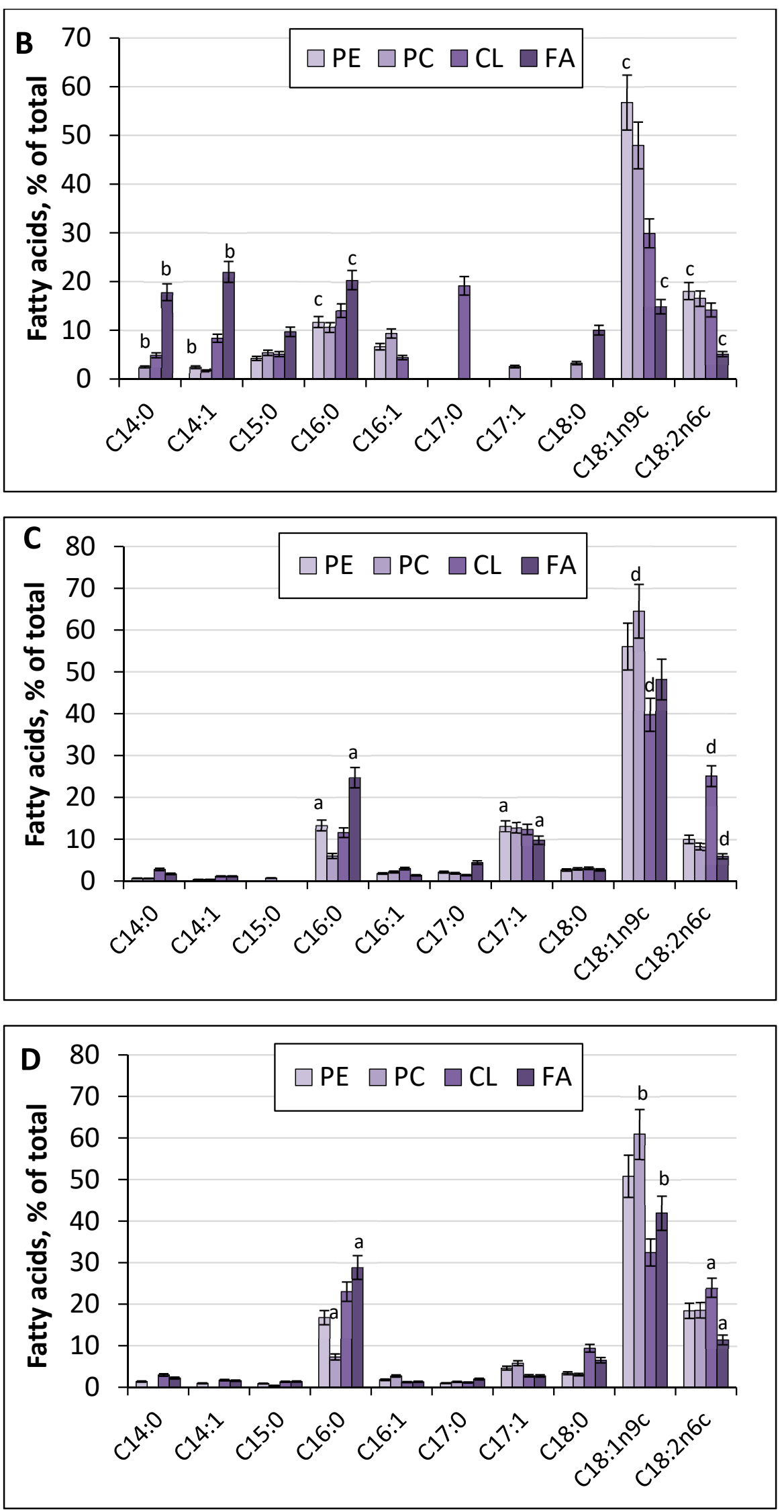

Figure 5. Cont. 


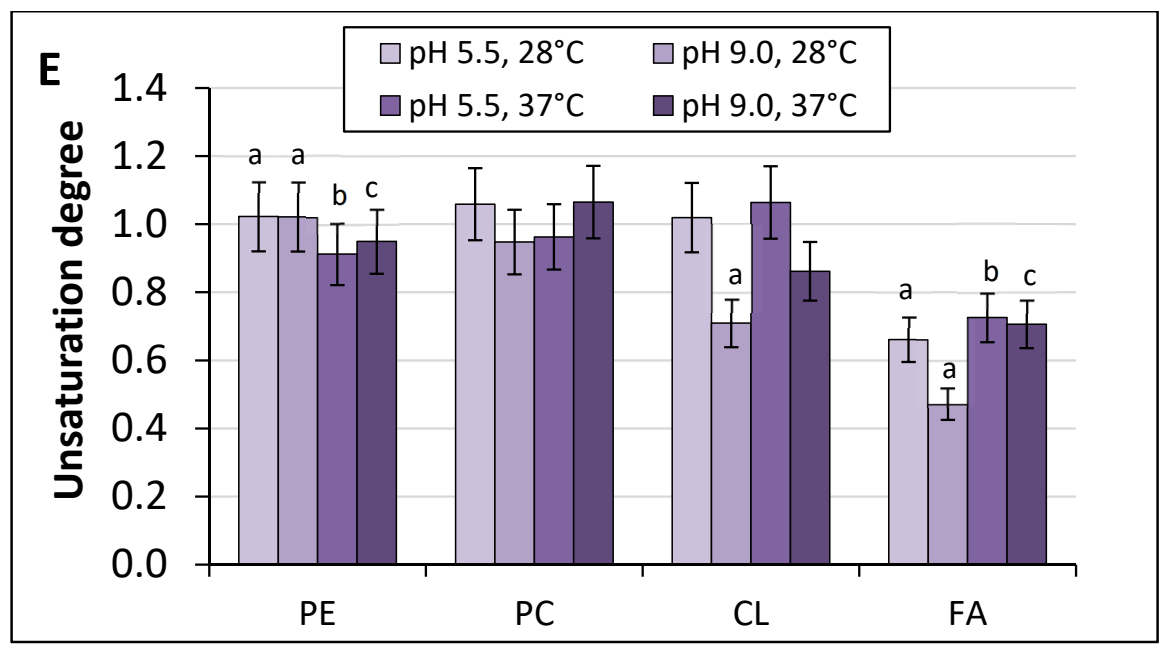

Figure 5. Fatty acid composition of the main membrane phospholipids of Y. lipolytica W29 (\% of total

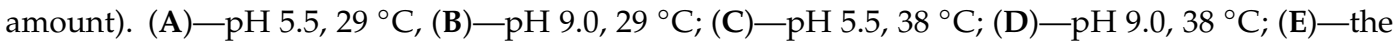
unsaturation degree. $\mathrm{a}-p<0.05 ; \mathrm{b}-p<0.001 ; \mathrm{c}-p<0.0004 ; \mathrm{d}-p<0.04$.

\section{Discussion}

Natural Y. lipolytica W29 yeast dwells in oily habitats, namely some food (cheese, yogurt, and sauces), wastewater contaminated with oils, as well as marine and hyper-mineralized sources [35,36]. Alkali- and halo-tolerance properties [1] make this organism a very promising model for biotechnological use [37]. In the present study, we could confirm the $Y$. lipolytica yeast's successful resistance to alkaline stress $(\mathrm{pH} \geq 8.0)$. Y. lipolytica possesses a broad optimum of the growth rate at various $\mathrm{pH}$ within 4.5 to 6.5 (Figure 1A). It let us render Y. lipolytica as a moderate alkali-tolerant [37]. This was unexpected, as it is postulated that most species of the Yarrowia genus grow at the temperature not higher than $32{ }^{\circ} \mathrm{C}[38,39]$. It indicates a high thermotolerance of Y. lipolytica W29 grown at both $\mathrm{pH} 5.5$ and 9.0.

\subsection{Cytosol Carbohydrate Profile}

Analysis of sugar compositions in Y. lypolytica at the optimal temperature showed that mannitol is the major soluble carbohydrate at any ambient $\mathrm{pH}$ tested. Polyol mannitol is reported to dominate not only in Y. lipolytica but also in Yarrowia divulgata $\left(28 \mathrm{~g} \times \mathrm{L}^{-1}, \mathrm{YP} / \mathrm{S}=0.25 \mathrm{~g} \times \mathrm{L}^{-1}\right)$, Candida hollandica $\left(34.2 \mathrm{~g} \times \mathrm{L}^{-1}, \mathrm{YP} / \mathrm{S}=0.31 \mathrm{~g} \times \mathrm{L}^{-1}\right)$, and Candida oslonensis $\left(34.3 \mathrm{~g} \times \mathrm{L}^{-1}, \mathrm{YP} / \mathrm{S}=0.29 \mathrm{~g} \times \mathrm{L}^{-1}\right)$ [2]. Moreover, mannitol comprises more than half of the total sugar amount in the cytosol of some alkali-tolerant fungi, namely Acrostalagmus luteoalbus, Chordomyces antarcticus, and alkaliphile species of Sodiomyces magadii and S. alkalinus. Its relative composition increased while $\mathrm{pH}$ lowed to acidic $\mathrm{pH}$ [20]. The mannitol level in Y. lipolytica also increased at elevated concentrations of sodium chloride [12]. Recently, mannitol has been known to be involved in quenching ROS, both in vitro and in vivo $[9,14]$. The protective effect of mannitol and the underlying mechanism are widely discussed. According to one of the main hypotheses, mannitol functions as a so-called "compatible" solute, which accumulates in high cellular concentrations when the organism is exposed to stress. According to another hypothesis, mannitol acts as an antioxidant [9]. Compatible compounds, including carbohydrates, polyols, amino acids, and their derivatives, have an important osmoprotective function in osmotolerant organisms, such as yeast and algae [9]. Some researchers interpret the effect of mannitol as a powerful "quencher" of hydroxyl radicals $\left(\mathrm{HO}^{\bullet}\right)$ due to a high reaction rate in in vitro experiments [9]. Probably, both hypotheses are correct, and mannitol can be localized in a cell at the specific site of high $\mathrm{HO}^{\bullet}$ production or in the close vicinity of the key $\mathrm{HO}^{\bullet}$ target molecules [9]. Based on our previous studies [40], we could suppose that constitutively high concentrations of mannitol in the Y. lipolytica yeast facilitated its resistance to extreme conditions by effective scavenging of ROS generated at extreme $\mathrm{pH}$. No significant difference in the mannitol concentration in the culture grown at different $\mathrm{pH}$ (Figure 2) suggests that the role 
of mannitol as a factor of $\mathrm{pH}$ adaptation should be excluded. At both normal and alkaline ambient $\mathrm{pH}$, it led to significant changes in the cytosol sugar profile. An increase in the total content of soluble carbohydrates is accompanied by the substitution of the dominant cytosol sugar for disaccharide trehalose, the significant rise in the arabitol fraction, and the disappearance of both mannitol and glucose. Under the thermal influence, the Y. lipolytica yeast showed that trehalose substituted the dominant mannitol in the sugar repertoire with a concurrent decrease in the glucose level. It suggests that trehalose could be either formed de novo or from mannitol to stabilize the membrane structures [8]. Trehalose is known to serve as a protector against elevated temperatures by stabilizing membrane proteins and lipids [41]. Recent studies using $S$. cerevisiae have revealed the role of the first enzyme of trehalose synthesis, trehalose- 6 phosphatase synthase, in the regulation of respiration and fermentation processes. S. cerevisiae mutants in tps1 exhibited impaired ethanol production, showed diminished plasma membrane $\mathrm{H}^{+}$-ATPase activation, and changed cell $\mathrm{pH}$-homeostasis [42]. The genes encoding trehalose synthesis are known to also be present in the Y. lipolytica genome, but the trehalose content in the cells using either glycerol or glucose is usually below $1 \mathrm{nmol} / \mathrm{mg}$ dry weight, which could be explained by a low activity of the biosynthesis pathway and high trehalase activity [43]. However, it increased upon disruption of a gene encoding a putative trehalase or after thermal shock [43]. Thermal shock causes an increase in the trehalose level in several yeast species [44]. In Y. lipolytica, a thermal shock of $40{ }^{\circ} \mathrm{C}$ for $2 \mathrm{~h}$ increased trehalose, varying from 7 to $20 \mathrm{nmol} / \mathrm{mg}$ dry weight in different strains [37]. The data are in good agreement with our results of the trehalose accumulation as the dominant sugar in the Y. lipolytica cytosol at the elevated temperature. Thus, when the growth temperature increased to $38^{\circ} \mathrm{C}$, a crucial change in the cytosolic sugar profile occurred.

Nevertheless, in the present study, we showed that trehalose, as a unique component of cell adaptation to any stress, found no confirmation. Although an alkaline condition is unfavorable for Y. lipolytica, which is proved by increasing the superoxide anion generation as antioxidant enzyme activities under these conditions [45], no trehalose was revealed in the cells grown at the optimal temperature at both $\mathrm{pH}$ tested. We also observed an increase in the arabitol level at the alkaline, thermal stresses, and their combination (Figure 2B). The accumulation of $D$-arabitol and trehalose was shown for the Debaryomyces and Geotrichum fungi [46], the Kluyveromyces lactis yeast [47], and the Candida albicans yeast [10] to the exposure of thermal, oxidative, and osmotic stress factors. In the eukaryotic cells, $D$-arabitol is known as a by-product of the pentose phosphate pathway in some processes, such as a supply of the pool of NADPH-reducing equivalents [40]. It is similar to mannitol, which can be oxidized to fructose, and is also capable of reducing NADP to NADPH [16]. NADPH, in turn, participates in restoring GSSG, a universal molecule maintaining the cellular redox potential. Interestingly, the redox potential of HSSG/GSH increased up to 0.48 at alkaline $\mathrm{pH}$ and 0.67 at the elevated temperature compared to 0.24 under the optimal conditions (Table 1). However, the ratio of the reduced glutathione to the oxidized one decreases more than two-fold. It could indicate the detoxification of ROS under stress. The obtained data indicate the development of the anti-stress response in the Y. lipolytica yeast under stress conditions that could confirm this statement (Table 1). Yeast cells under different kinds of stress may generate abundant GSH, which is involved in the cell protection against the damage from $\mathrm{O}^{2-}$. The high level of GSH could be a marker of an acute oxidative stress [48]. The data suggest that under optimal conditions, mannitol, the synthesis pathway of which is branched from the glycolysis at the glucose-6-phosphate stage, is of great importance for the development of Y. lipolytica [16]. Under thermal shock conditions, the cells should, first of all, provide the membrane structure stability for the transporters to work, which is often achieved by trehalose accumulation in the cells. Since cellular trehalose is not consumed, but largely serves as a stabilizer [8], we suppose that the pentose-phosphate pathway is induced to restore reducing equivalents, which in turn leads to $D$-arabitol accumulation [46].

Our results showed that upon growth at elevated temperatures, both trehalose, which serves as an antioxidant, osmolyte, and membrane stabilizer, and arabitol, which is an osmolyte [46], play a vital role in the adaptation of the Y. lipolytica yeast to thermal shock. 


\subsection{Lipidome of Y. lipolytica}

The results of our studies showed that glycerol-utilizing Y. lipolytica cells had a high lipid content. This is in accordance with the data by $[49,50]$, which showed a high yield of synthesized intracellular lipids upon assimilation of glycerol by Rodotorula and Sporobolomyces yeast. It may be related to the fact that glycerol used as a growth carbon substrate promotes the lipid synthesis in the yeast cell. Thus, glycerol can diffuse through the cytosolic membranes of a yeast cell and then may transform into some lipids, including unsaturated fatty acids [51].

The alkaline $\mathrm{pH}$ adaptation of $Y$. lipolytica caused a general decrease in the storage lipid profile (Figure 3). The similar decrease in the total storage lipids at alkaline ambient $\mathrm{pH}$ was also demonstrated for the Sodiomyces tronii ascomycete [20]. The decrease in DAG levels in storage lipids under thermal and combined stresses suggested that under these conditions, the cells could use the storage lipids as substrates (Figure 3A). The data are confirmed by the results of ultra-structural changes in the Y. lipolytica yeast under stress with a concurrent reduction in the number and volume of the LBs (Figure 3D-F). Abundant LBs could be observed in the yeast cytoplasm (Figure 3C-F). The lipid droplets mainly participate in the storage and release of accumulated nutrients, being an energy source in the yeast cells $[28,29]$. Moreover, they are used as substrates to synthesize lipid components for cellular membranes. The LBs, along with some various organelles, play the key role in lipid metabolism and the maintenance of cellular energy homeostasis as well as in protein content circulation. Since the compartment stores energy, it can support and regulate the membrane composition. Besides that, it promotes lipid accumulation, resulting in an efficient adaptation and assimilation of hydrophobic substrates, like $n$-alkanes, fatty acids, and triglycerides [28,29]. The recent paper by [52] reported a stress-induced metabolic shift from fermentation to respiration, including the induction of peroxisomal $\beta$-oxidation of fatty acids. It stimulates mitochondrial respiration via alternative carbon sources and the activation of retrograde signaling to alleviate mitochondria damage [52]. Probably, in the case of adaptation of the $Y$. lipolytica yeast to extreme $\mathrm{pH}$ and elevated temperatures, a similar mechanism may work.

The amount of membrane lipids also decreased at alkaline $\mathrm{pH}$ (Figure 4B). The membrane lipids repertoire under the conditions varied slightly. However, the conditions of simultaneous $\mathrm{pH} 9.0$ and an elevated temperature caused a two-fold decrease in the CL fraction of the mitochondrial membranes compared to the optimal conditions. CL is known to function as a proton trap as it has four acyl residues and two orthophosphoric acid residues, each capable of binding one proton [53]. It lets CL create a proton gradient on both the inner and outer mitochondrial membranes. CL plays a vital role in the mitochondrial functions and biogenesis of organelles by interacting with a wide range of mitochondrial proteins both via hydrophobic and electrostatic interactions and by stabilizing the mitochondrial respiratory chain proteins [54]. In 2012, Rostovtseva and Bezrukov [55] showed that CL-rich areas of the outer mitochondrial membrane manifested an increased activity of the mitochondrial porin of VDAC, which participated in scavenging the superoxide anion radical from the mitochondria. The CL fatty acids' composition significantly influences the VDAC functions [54]. In our study, alkaline $\mathrm{pH}$ caused some changes in the fatty acid composition of the $\mathrm{CL}$ fraction. Thus, at $\mathrm{pH} 9.0$, the margaric acid (C17:0) share reached 14\% when compared to that at normal $\mathrm{pH}$, which was equal to zero. The lauric, myristic, pentadecanoic, and palmitic acid fractions significantly decreased (Figure 5B). Earlier, Marek Kieliszek showed an increase in the margaric and heptadecenoic (C17:1) acid levels in Candida utilis grown either using $5 \%$ glycerol as a carbon source or enriched with selenium $(20 \mathrm{mg} / \mathrm{L})$ by two times and by $25 \%$, respectively [28]. Also, abundant margaric (C17: $0 ; 12.19 \%)$ and heptadecenoic (C17:1; $9.31 \%$ ) fatty acids were found when Y. lipolytica was cultivated in fermenters using glycerol as a carbon source. Probably, an increase in the saturated fatty acid content of the mitochondria CL fraction upon stress provides the integrity and rigidity of the cell membranes according to the homeoviscous adaptation, which includes a change in the lipid profile of the cell membrane, ensuring its necessary fluidity [56]. 
The elevated growth temperatures caused a significant increase in the PC fraction and a decrease in the St one in the membrane lipid profile. PC are PL synthesized from the PE in the endoplasmic reticulum via the Kennedy pathway [57]. The homeostatic equilibrium between the two classes of PL is of great importance for both performing mitochondrial functions and protecting against oxidative stress that was reported for C. albicans. The PC level increase was also reported for S. cerevisiae under stress induced by the p-HPCD detergent treatment [58]. PCs are bilayer lipids, which ensure the stability of the membrane structure [59]. Probably, in our case, both an increase in the PC fraction and a decrease in the St one could compensate for the drop in the lipid acyl chain's unsaturation in the membranes. The fact that the fatty acids of the PC fraction at optimal temperature maintain the highest degree of unsaturation could partly confirm this speculation (Figure 5E). As far as minor membrane lipids, there was also some increase in the PA fraction in the membrane lipids under both thermal and combined stresses. The data are agree well with the results obtained by [60], where the authors using the Aspergilus niger fungus showed that various stressful factors (heat and cold shock, oxidative and osmotic stress) led to a significant increase in the PA level in the membranes. They speculated that the PAs contributed to the fungus adaptive defense responses to stress by increasing the cell membrane stability and by intensifying vesicular transport, and endo- and exocytosis. Probably, in the case of adaptation to thermal shock and alkaline stress in Y. lipolytica, a similar mechanism may occur. The changes in the IndexIHD of the acyl chains of membrane lipids depend on the kind of stress factor used. The extreme $\mathrm{pH}$ values affected the degree of unsaturation insignificantly, except for $\mathrm{CL}$, where the total IHD of acyl chains decreased by nearly two-fold at pH 9.0 (Figure 5B,D).

In the paper by [61], the authors showed the influence of a variety of growth conditions used on the yeast lipidome, when the growth temperature led to an increase in fatty acid unsaturation as well as shortening of the chains. The overall decrease in IHD of the acyl chains of the membrane lipids under the elevated temperature could be explained by the fact that the higher unsaturation degree results in a lower melting point of the membrane. It means that it becomes much more difficult for a cell to maintain a structural organization and optimal function of cellular membranes. Similar experimental results were obtained using Schizosaccharomyces pombe exposed to a short temperature stress. The data demonstrated an increase in the saturated fatty acids share in the membrane lipids [56].

Interestingly, the elevated temperature and alkaline $\mathrm{pH}$ strongly altered both the qualitative and quantitative lipid profiles of the Y. lipolytica cells (Figures 3-5). The data suggest that the thermal shock could manifest the most pronounced response in Y. lipolytica, leading to metabolic readjustments, including increased membrane rigidity, in particular, due to the appearance of some saturated fatty acids, namely penta-decanoic (C14:0) and margaric (C17:0) acids, in the lipid profile and an increase in the palmitic (C16:0) acid content (Figure 5C,D).

\section{Conclusions}

The adaptation strategy of the Y. lipolytica yeast to various unfavorable conditions has been studied before in [53], where the authors suggested that there was a certain general defense response to different stress factors (temperature shock, ethanol, and oxidative stress) of the yeast strain, yielding the organism the advantage of poly-extremophilicity. The adaptation mechanism includes the reduction of cyclic adenosine monophosphate (cAMP), an increase in the antioxidant enzyme activity, and induction of the alternative pathway for electron transfer in the mitochondria [62]. The adaptive strategy is non-specific and uses a general "activating center".

Based on the experimental evidence, we conclude that the $Y$. lipolytica yeast can use different kinds of defense responses for long-term adaptation to unfavorable environmental conditions, such as alkaline $\mathrm{pH}$ and elevated temperature. The lipid and carbohydrate cellular profiles reflect the changes forming different and highly specific adaptive responses, accompanied by modifications of both the cell antioxidant state and oxidized and reduced glutathione levels (Table 1). Interestingly, under the cross-adaptation of Y. lipolytica to the combined stress, the thermal shock is evidently dominating. The elevated temperature affects the adaptive strategy of the cell, probably due to the natural alkali 
tolerance of the species. The changes in $\mathrm{pH}$ cause only some fluctuations in IHD of the lipid acyl chains while the thermal shock leads to dramatic metabolic readjustments in the sugar and lipid profiles, and in particular, the substitution of the main carbohydrates, crucial changes in the membrane lipids, and their IHD.

It is worth noting that managing the sugar and lipid composition in Y. lipolytica W29 can play a significant role in the application of this organism into industry. Recently, quite promising results were obtained concerning the use of the extremophile Y.lipolytica as a mannitol producer [62]. The authors showed that Y.lipolytica, grown in glycerol-containing medium at alkaline $\mathrm{pH}$, enables the production of a significant amount of mannitol $(27.6 \mathrm{~g} / \mathrm{L})$. It could provide the basis for developing alternative and innovative technologies of mannitol production. Mannitol is a polyol, which is in great demand by the modern food, pharmaceutical, and medical industry. The biosynthesis of polyunsaturated fatty acids using Y. lipolytica W29, induced in elevated temperature cultivation, can be used to produce the enriched products, which are highly sought for medical purposes.

\section{Materials and Methods}

\subsection{Yeast Strains and Growth Conditions}

Wild-type Yarrowia lipolytica W 29 from CIRM Levures collection (France) was used. The culture was raised in batches of $100 \mathrm{~mL}$ in glycerol (1\%)-containing medium of the following composition (g/L): $\left.\mathrm{MgSO}_{4}-0.5,\left(\mathrm{NH}_{4}\right)_{2} \mathrm{SO}_{4}-0.3, \mathrm{KH}_{2} \mathrm{PO}_{4}-2.0, \mathrm{~K}_{2} \mathrm{HPO}_{4}-0.5, \mathrm{NaCl}-0.1, \mathrm{CaCl}_{2}-0.05\right)$. Then, $2 \mathrm{M} \mathrm{KP}_{\mathrm{i}}$ stock buffer was prepared by dissolving $\mathrm{KH}_{2} \mathrm{PO}_{4}$ anhydrous $(272 \mathrm{~g} / \mathrm{L}$, Amresco Cat \# 0781), $\mathrm{pH}$ adjusted with $2 \mathrm{M} \mathrm{K}_{2} \mathrm{HPO}_{4}$ to 6.0. Further, $2 \mathrm{M} \mathrm{KP}_{\mathrm{i}}$ stock buffer was prepared by dissolving $\mathrm{K}_{2} \mathrm{HPO}_{4}$ anhydrous (342 g/L, Amresco Cat \# 0705), $\mathrm{pH}$ adjusted with $2 \mathrm{M} \mathrm{KH}_{2} \mathrm{PO}_{4}$ to 9.0. Both $\mathrm{KP}_{\mathrm{i}}$ buffers were sterilized by autoclaving and added to sterilize the culture medium (ratio 1:40) just before inoculation. The yeast was cultivated at different ambient $\mathrm{pH}$ from 3.0 to 9.0 on a rotary shaker at 150 r.p.m at temperatures of 29 and $38^{\circ} \mathrm{C}$ as described in [63]. Absorbance (A) was assessed in cell suspension at the wavelength of $590 \mathrm{~nm}\left(\mathrm{~A}_{590}\right)$ using a Specol-11 spectrophotometer (Germany). The yeast was raised in the stationary growth phase.

\subsection{Cell Viability and Vitality Assays}

To determine culture viability, the yeast cells from the stationary phase were centrifuged, washed with sterile water, and suspended to the final density of $10^{8}$ cells $\mathrm{mL}^{-1}$ in $100 \mathrm{mM} \mathrm{KP} \mathrm{i}_{\mathrm{i}}$ buffer; $\mathrm{pH}$ 7.0. To determine cell viability and vitality, the following methods were used [64].

\subsubsection{Spotting Test}

Cells were suspended in sterile water and diluted to give $10^{5}, 10^{4}$, or $10^{3}$ cells $\mathrm{mL}^{-1}$. Samples $(10 \mu \mathrm{L})$ of each suspension were inoculated on solid YPD medium with pH 5.5 and 9.0 and incubated at $29^{\circ} \mathrm{C}$. Colony growth was inspected after $48 \mathrm{~h}$.

\subsubsection{Staining with Methyl Blue}

Yeast cells were suspended in phosphate-buffered saline (PBS), and a 200- $\mu \mathrm{L}$ sample of the cell suspension was mixed with $100 \mu \mathrm{L}$ methylene blue $\left(0.1 \mathrm{mg} \mathrm{mL}^{-1}\right.$ stock solution, dissolved in a $2 \%$ dihydrate sodium citrate solution) and incubated for $5 \mathrm{~min}$ at room temperature. Viability was examined under a light microscope using Gorjaev's chamber $(\times 400)$ from at least 1000 cells in one biological replicate. Viable cells were colorless, and dead ones were blue.

\subsection{Potential-Dependent Staining}

Potential-dependent staining of mitochondria in the Y. lipolytica cells using Rh123. Cells were incubated with $0.5 \mu \mathrm{M}$ Rh123 and examined in $30 \mathrm{~min}$. The incubation medium contained $0.01 \mathrm{M}$ PBS, $\mathrm{pH} 7.4$, and $1 \%$ glycerol. Regions of high mitochondrial polarization are indicated by red fluorescence 
due to the concentrated dye. To examine the Rh123-stained preparations, filters 02,15 (Zeiss) were used (magnification $\times 100$ ). The photos were taken using an AxioCam MRC camera [65].

\subsection{Transmission Electron Microscopy (TEM)}

TEM analyses of the Y. lipolityca cells were performed as described previously [66] and were examined using Jeol (JEM-100 B; Tokyo, Japan) and Hitachi U-12 (Tokyo, Japan) electron microscopes.

\subsection{Preparation of Cellular Homogenate}

The cellular homogenate was obtained as follows: Cells were washed twice with ice-cold water, and resuspended in grinding medium (1:1 w/v). The medium contained: $10 \mathrm{mM}$ MES, $0.5 \mathrm{M}$ mannitol, $5 \mathrm{mM}$ EDTA, and $0.5 \mathrm{mM}$ phenyl-methylsulfonyl-fluoride (PMSF); $\mathrm{pH}$ 6.5. The yeast cells were disrupted with an ultrasonic disintegrator 9 MSE (Farmacia, Sweden) using some pulses at $0{ }^{\circ} \mathrm{C}$ for 2 min interrupted by cooling periods every $30 \mathrm{~s}$. The obtained homogenate was centrifuged at $10,000 \times g$ for $30 \mathrm{~min}$ and the supernatant was collected for further experiments [65].

\subsection{Enzymes Activities Assay}

Total catalases (CATs) and superoxide dismutases (SODs) activities in cell suspension were assessed according to [65].

\subsection{Glutathione HPLC-ECD Analysis}

The harvested yeast cells were briefly washed with deionized water and frozen in liquid nitrogen for further HPLC analysis. Then, $100 \mu \mathrm{L}$ of re-frozen yeast lysate was added to $500 \mu \mathrm{L}$ of $0.1 \mathrm{M}$ cold iced perchloric acid (PCA). After brief vortexing, suspension was sonicated for $5 \mathrm{~s}$ and placed on ice for 10 to $15 \mathrm{~min}$ for better metabolite extraction. The obtained cell homogenate was centrifuged twice for $20 \mathrm{~min}$ at $14,000 \mathrm{rpm}$ in precooled $\left(+4^{\circ} \mathrm{C}\right)$ micro centrifuge. Then, $200 \mu \mathrm{L}$ of clear supernatant was loaded into HPLC vial for direct HPLC analysis. The HPLC system for glutathione measurements was equipped with a CouloChem-III electrochemical detector, Waters 717 plus auto-sampler with a cooled platform $\left(+4{ }^{\circ} \mathrm{C}\right)$ and Waters $515 \mathrm{HPLC}$ pump. In total, $20 \mu \mathrm{L}$ of mobile phase $\left(0.1 \mathrm{M} \mathrm{LiH}_{2} \mathrm{PO}_{4}\right.$, $1.5 \mathrm{mM}$ octenylsuccinic anhydride, and $7 \%$ methanol) was delivered at flow rate of $1.0 \mathrm{~mL} / \mathrm{min}$ in an isocratic mode. Pre-column was Super ODS A0114; $4.6 \mathrm{~mm} \times 5 \mathrm{~cm}$, particle size $2 \mu \mathrm{m}$ and analytical column was ESA HR-80; $80 \mathrm{~mm} \times 4.6 \mathrm{~cm}, \mathrm{P} / \mathrm{N} 68-0100$ with particle size $3 \mu \mathrm{m}$ and pore size $120 \mathrm{~A}$. Both columns were maintained at $+30^{\circ} \mathrm{C}$. Under the conditions, GSH eluted at $1.61 \mathrm{~min}$ and GSSG at $2.72 \mathrm{~min}$. Sample processing, files storage, and data analysis were controlled by EZChrom Elite software (Dionex \& Thermo Fisher Scientific Company, Bedford, MA, USA). The concentration of GSH and GSSG was calculated based on a calibration curve equation per $\mathrm{mg}$ of protein.

\subsection{Preparation and Analysis of Lipids}

To determine cell lipids, yeast cells in the stationary growth phase were raised and centrifuged at $6000 \times g$, washed twice with cold distilled water, and frozen liquid nitrogen [67]. The weighted sample of about $1 \mathrm{~g}$ was immediately homogenized in isopropanol to de-activate lipases by pestle and mortar, and incubated at $70{ }^{\circ} \mathrm{C}$ for $30 \mathrm{~min}$. Then, the biomass was homogenized once more using some sand and the lipids were extracted by the method described in [67], which involved extraction with isopropanol and the isopropanol-chloroform mixture $(1: 1$ and $1: 2)$ at $70{ }^{\circ} \mathrm{C}$, evaporation in a rotary evaporator, and extraction of the residue with chloroform-methanol (1:1) supplemented with $5 \%$ sodium chloride solution and water to remove water-soluble substances. After separating the mixture with a vortex, we dried the chloroform layer by passing it through water-free sodium sulphate, evaporated, and desiccated with a vacuum pump. The resulting pellet dissolved in a small amount of chloroform-methanol (1:1) was stored at $-21{ }^{\circ} \mathrm{C}$. The composition of storage lipids was assayed using an ascending thin layer chromatography on glass plates with silica gel 60 ("Merck", Darmstadt, 
Germany). To separate storage lipids, the hexane:sulphuric ether:acetic acid (85:15:1) system [68] was used. To separate phospholipids and sphingolipids, SI60 Silica thin layer chromatography plates were activated and developed in two dimensions, first with chloroform/methanol/water (65/25/4, by volume) and second with chloroform/acetone/methanol/acetic acid/water 950/20/10/10/5, by volume) [69]. The lipids (100-200 $\mu \mathrm{g})$ were applied to a plate bovine serum glycoceramides, and PC used as sphingolipid (SL) and phospholipid (PL) standards were applied on chromatograms before passing in the second direction. Samples of SL (5 and $10 \mu \mathrm{g})$ and PC (10 and $20 \mu \mathrm{g})$ were applied on the plates. To develop the stains, the chromatograms were sprayed with $5 \%$ sulfuric acid in ethanol, followed by heating up to $180^{\circ} \mathrm{C}$. To detect phospholipids, the developed thin-layer plates were sprayed with $0.1 \%$ $(w / v)$ ninhydrin for the ones carrying free amino groups and with $\alpha$-naphtol for glycolipids. Lipids containing a quaternary ammonium group were visualized at room temperature with Dragendorff's spray reagent [70]. Sphingolipids were detected in the glycolipid fraction by the saponification method [71]. Storage lipids were identified with individual markers for di- and triglycerides (DAG, TAG), sterols (ergosterol), free fatty acids (FFA), and hydrocarbons ("Sigma", Sant Louis, MO, USA). Quantitative analysis of the lipids was performed using the Dens software ("Lenchrom", S-Peterburg, Russia). Thin-layer chromatography (TLC) plates of storage lipids were added to the Supplementary (Figure S1). To assess the fatty acid composition of PL, separate PL were isolated using chromatography with two plates, and eluted with chloroform/methanol $(1 / 1, v / v)$ for a night. Then, the supernatant was decanted, evaporated, $1 \mathrm{~mL}$ toluene and $2 \mathrm{~mL}$ of $2.5 \% \mathrm{H}_{2} \mathrm{SO}_{4}$ dissolved in methanol, and kept for two hours at $+70^{\circ} \mathrm{C}$. Fatty acid methyl ethers were extracted with hexane, dried, and analyzed by a Kristall 5000.1 gas chromatograph ("Chromatek", Yoshkar-Ola, Russia) using an Optima-240 (60 m $\times 0.25 \mathrm{~mm}$ ) capillary column ("Macherey-Nagel GmbH \& Co.", Duren, Germany). The temperature program was set from +130 to $+240{ }^{\circ} \mathrm{C}$. Eluting fatty acids were identified using the Supelco 37 Component FAME Mix (a mixture of fatty acid methyl esters) ("Supelco", Sant Louis, MO, USA).

\subsection{Carbohydrate Analysis}

The sugars were obtained by repeated four-time extraction with boiling water for $20 \mathrm{~min}$. Proteins were removed from the resulting extract [70]. The extract was further purified of charged compounds using a combined column with the Dowex- 1 (acetate form) and Dowex $50 \mathrm{~W}\left(\mathrm{H}^{+}\right)$ ion exchange resins. The sugar composition was determined by gas-liquid chromatography using trimethylsilyl sugar derivatives obtained from the lyophilized extract [71]. $\alpha$-Methyl- $D$-mannoside ("Merck", Darmstadt, Germany) served as the internal standard. Chromatography was performed with a Kristall 5000.1 gas chromatograph ("Chromatek", Yoshkar-Ola, Russia) equipped with a ZB-5 $30 \times 0.32 \mathrm{~mm}$ capillary column ("Phenomenex", Torrance, CA, USA) temperature program was set at $+130,5-6{ }^{\circ} \mathrm{C} / \mathrm{min}$ gradient to $+270{ }^{\circ} \mathrm{C}$. Glucose, mannitol, arabitol, inositol, and trehalose ("Sigma", Sant Louis, MO, USA) served as the standards.

\subsection{Statistical Analyses}

Data are presented as the average \pm standard deviation in biological triplicates with a standard error of less than $5 \%$. Analysis of soluble carbohydrates and lipids was performed using one-way ANOVA $(n=3)$. $p$ values were determined by the two-tailed paired $\mathrm{t}$-test at the $5 \%$ level of probability.

Supplementary Materials: The following are available online at http://www.mdpi.com/2218-1989/9/12/307/s1, Figure S1: TLC plates of storage lipids.

Author Contributions: Conceptualization, V.Y.S. and V.M.T.; Formal analysis, N.N.G.; Investigation, V.Y.S., D.I.D., E.P.I. and N.N.G.; Methodology, D.I.D. and E.P.I.; Supervision, V.M.T. and Y.I.D.; Writing-original draft, V.Y.S., D.I.D.; N.N.G. and Y.I.D.; Writing-review \& editing, E.P.I., V.M.T. and Y.I.D.

Funding: This research was partially supported by the RFBR grant "mol_ev_a"\#19-34-80012.

Conflicts of Interest: The authors declare no conflict of interest. The funders had no role in the design of the study; in the collection, analyses, or interpretation of data; in the writing of the manuscript, or in the decision to publish the results. 


\section{References}

1. Zvyagilskaya, R.A.; Parkhomenko, O.A.; Gordeeva, A.V.; Deryabina, Y.I.; Persson, B.L. Bioenergetics of Yarrowia lipolytica cells grown at alkaline condition. Biosci. Rep. 2004, 24, 117-122. [CrossRef] [PubMed]

2. Egermeier, M.; Russmayer, H.; Sauer, M.; Marx, H. Metabolic flexibility of Yarrowia lipolytica growing on glycerol. Front. Microbiol. 2017, 8, 49. [CrossRef] [PubMed]

3. Liu, H.H.; Ji, X.J.; Huang, H. Biotechnological applications of Yarrowia lipolytica: Past, present and future. Biotechnol. Adv. 2015, 33, 1522-1546. [CrossRef] [PubMed]

4. Zhu, Q.; Jackson, E.N. Metabolic engineering of Yarrowia lipolytica for industrial applications. Curr. Opin. Biotechnol. 2015, 36, 65-72. [CrossRef] [PubMed]

5. Madzak, C. Engineering Yarrowia lipolytica for use in biotechnological applications: A review of major achievements and recent innovations. Mol. Biotechnol. 2018, 60, 621-635. [CrossRef] [PubMed]

6. Brown, A.J.P.; Cowen, L.E.; di Pietro, A.; Quinn, J. Stress Adaptation. Microbiol. Spectr. 2017, 5. [CrossRef]

7. Kobayashi, Y.; Iwata, H.; Yoshida, J.; Ogihara, J.; Kato, J.; Kasumi, T. Metabolic correlation between polyol and energy-storing carbohydrate under osmotic and oxidative stress condition in Moniliella megachiliensis. J. Biosci. Bioeng. 2015, 120, 405-410. [CrossRef]

8. Eleutherio, E.; Panek, A.; De Mesquita, J.F.; Trevisol, E.; Magalhães, R. Revisiting yeast trehalose metabolism. Curr. Genet. 2015, 61, 263-274. [CrossRef]

9. Patel, T.K.; Williamson, J.D. Mannitol in plants, fungi, and plant-fungal interactions. Trends Plant. Sci. 2016, 21, 486-497. [CrossRef]

10. Sánchez-Fresneda, R.; Guirao-Abad, J.P.; Argüelles, A.; González-Párraga, P.; Valentín, E.; Argüelles, J.C. Specific stress-induced storage of trehalose, glycerol and $D$-arabitol in response to oxidative and osmotic stress in Candida albicans. Biochem. Biophys. Res. Commun. 2012, 430, 1334-1339. [CrossRef]

11. Kayingo, G.; Kilian, S.G.; Prior, B.A. Conservation and release of osmolytes by yeasts during hypo-osmotic stress. Arch. Microbiol. 2001, 177, 29-35. [CrossRef] [PubMed]

12. Tomaszewska, L.; Rakicka, M.; Rymowicz, W.; Rywińska, A. A comparative study on glycerol metabolism to erythritol and citric acid in Yarrowia lipolytica yeast cells. FEMS Yeast Res. 2014, 14, 966-976. [CrossRef] [PubMed]

13. Solomon, P.S.; Waters, O.D.; Oliver, R.P. Decoding the mannitol enigma in filamentous fungi. Trends Microbiol. 2007, 15, 257-262. [CrossRef] [PubMed]

14. Meena, M.; Prasad, V.; Zehra, A.; Gupta, V.K.; Upadhyay, R.S. Mannitol metabolism during pathogenic fungal-host interactions under stressed conditions. Front. Microbiol. 2015, 6, 1019. [CrossRef] [PubMed]

15. Vélëz, H.; Glassbrook, N.J.; Daub, M.E. Mannitol biosynthesis is required for plant pathogenicity by Alternaria alternata. FEMS Microbiol Lett. 2008, 285, 122-129. [CrossRef] [PubMed]

16. Voegele, R.T.; Hahn, M.; Lohaus, G.; Link, T.; Heiser, I.; Mendgen, K. Possible roles for mannitol and mannitol dehydrogenase in the biotrophic plant pathogen Uromyces fabae. Plant Physiol. 2005, 137, 190-198. [CrossRef]

17. Benaroudj, N.; Lee, D.H.; Goldberg, A.L. Trehalose accumulation during cellular stress protects cells and cellular proteins from damage by oxygen radicals. J. Biol. Chem. 2001, 276, 24261-24267. [CrossRef]

18. Pan, D.; Wiedemann, N.; Kammerer, B. Heat Stress-Induced Metabolic Remodeling in Saccharomyces cerevisiae. Metabolites 2019, 9, 266. [CrossRef]

19. Flores, C.L.; Gancedo, C.; Petit, T. Disruption of Yarrowia lipolytica TPS1 gene encoding trehalose-6-P synthase does not affect growth in glucose but impairs growth at high temperature. PLoS ONE 2011, 6, e23695. [CrossRef]

20. Bondarenko, S.A.; Ianutsevich, E.A.; Danilova, O.A.; Grum-Grzhimaylo, A.A.; Kotlova, E.R.; Kamzolkina, O.V.; Bilanenko, E.N.; Tereshina, V.M. Membrane lipids and soluble sugars dynamics of the alkaliphilic fungus Sodiomyces tronii in response to ambient $\mathrm{pH}$. Extremophiles 2017, 21, 743-754. [CrossRef]

21. Klose, C.; Surma, M.A.; Gerl, M.J.; Meyenhofer, F.; Shevchenko, A.; Simons, K. Flexibility of a eukaryotic lipidome-insights from yeast lipidomics. PLoS ONE 2012, 7, e35063. [CrossRef] [PubMed]

22. Henderson, C.M.; Block, D.E. Examining the role of membrane lipid composition in determining the ethanol tolerance of Saccharomyces cerevisiae. Appl. Environ. Microbiol. 2014, 80, 2966-2972. [CrossRef] [PubMed]

23. Koch, B.; Schmidt, C.; Daum, G. Storage lipids of yeasts: A survey of nonpolar lipid metabolism in Saccharomyces cerevisiae, Pichia pastoris, and Yarrowia lipolytica. FEMS Microbiol. 2014, 38, 892-915. [CrossRef] [PubMed] 
24. Kodedová, M.; Sychrová, H. Changes in the Sterol Composition of the Plasma Membrane Affect Membrane Potential, Salt Tolerance and the Activity of Multidrug Resistance Pumps in Saccharomyces cerevisiae. PLoS ONE 2015, 10, e0139306. [CrossRef]

25. Carman, G.M.; Han, G.S. Regulation of phospholipid synthesis in the yeast Saccharomyces cerevisiae. Annu. Rev. Biochem. 2011, 80, 859-883. [CrossRef]

26. Breslow, D.K.; Weissman, J.S. Membranes in balance: Mechanisms of sphingolipid homeostasis. Mol. Cell 2010, 40, 267-279. [CrossRef]

27. Henry, S.A.; Kohlwein, S.D.; Carman, G.M. Metabolism and regulation of glycerolipids in the yeast Saccharomyces cerevisiae. Genetics 2012, 190, 317-349. [CrossRef]

28. Gálvez-López, D.; Chávez-Meléndez, B.; Vázquez-Ovando, A.; Rosas-Quijano, R. The metabolism and genetic regulation of lipids in the oleaginous yeast Yarrowia lipolytica. Braz. J. Microbiol. 2019, 50, $23-31$. [CrossRef]

29. Kieliszek, M.; Błażejak, S.; Bzducha-Wróbel, A.; Kot, A.M. Effect of selenium on lipid and amino acid metabolism in yeast cells. Biol. Trace Elem. Res. 2019, 187, 316-327. [CrossRef]

30. Tezaki, S.; Iwama, R.; Kobayashi, S.; Shiwa, Y.; Yoshikawa, H.; Ohta, A.; Horiuchi, H.; Fukuda, R. $\Delta 12$-fatty acid desaturase is involved in growth at low temperature in yeast Yarrowia lipolytica. Biochem. Biophys. Res. Commun. 2017, 488, 165-170. [CrossRef]

31. Cordova, L.T.; Alper, H.S. Production of $\alpha$-linolenic acid in Yarrowia lipolytica using low temperature fermentation. Apple Microbiol. Biotechnol. 2018, 102, 8809-8816. [CrossRef] [PubMed]

32. Sun, M.-L.; Madzak, C.; Liu, H.-H.; Song, P.; Ren, L.-J.; Huang, H.; Ji, X.-J. Engineering Yarrowia lipolytica for efficient $\gamma$-linolenic acid production. Biochem. Eng. J. 2017, 117, 172-180. [CrossRef]

33. Moi, I.M.; Leow, A.T.C.; Ali, M.S.M.; Rahman, R.; Salleh, A.B.; Sabri, S. Polyunsaturated fatty acids in marine bacteria and strategies to enhance their production. Appl. Microbiol. Biotechnol. 2018, 102, 5811-5826. [CrossRef] [PubMed]

34. Grillitsch, K.; Connerth, M.; Köfeler, H.; Arrey, T.N.; Rietschel, B.; Wagner, B.; Karas, M.; Daum, G. Lipid particles/droplets of the yeast Saccharomyces cerevisiae revisited: Lipidome meets proteome. Biochim. Biophys. Acta 2011, 1811, 1165-1176. [CrossRef] [PubMed]

35. Nicaud, J.M. Yarrowia lipolytica. Yeast 2012, 29, 409-418. [CrossRef] [PubMed]

36. Gonçalves, F.A.G.; Colen, G.; Takahashi, J.A. Yarrowia lipolytica and its multiple applications in the biotechnological industry. Sci. World J. 2014. [CrossRef]

37. Grum-Grzhimaylo, O.A.; Debets, A.J.; Bilanenko, E.N. The diversity of microfungi in peatlands originated from the White Sea. Mycologia 2016, 108, 233-254. [CrossRef]

38. Augstein, A.; Barth, K.; Gentsch, M.; Kohlwein, S.D.; Barth, G. Characterization, localization and functional analysis of Gpr1 p, a protein affecting sensitivity to acetic acid in the yeast Yarrowia lipolytica. Microbiology 2003, 149, 589-600. [CrossRef]

39. Fickers, P.; Fudalej, F.; Nicaud, J.M.; Destain, J.; Thonart, P. Selection of new over-producing derivatives for the improvement of extracellular lipase production by the non-conventional yeast Yarrowia lipolytica. J. Biotechnol. 2005, 115, 379-386. [CrossRef]

40. Sekova, V.Y.; Dergacheva, D.I.; Isakova, E.P.; Deryabina, Y.I.; Tereshina, V.M. Carbohydrate spectrum of extremophilic yeasts Yarrowia lipolytica under pH-stress. Mikrobiologiya 2018, 87, 173-180. [CrossRef]

41. Yancey, P.H.; Siebenaller, J.F. Co-evolution of proteins and solutions: Protein adaptation versus cytoprotective micromolecules and their roles in marine organisms. J. Exp. Biol. 2015, 218, 1880-1896. [CrossRef] [PubMed]

42. Walther, T.; Mtimet, N.; Alkim, C.; Vax, A.; Loret, M.O.; Ullah, A.; Gancedo, C.; Smits, G.J.; François, J.M. Metabolic phenotypes of Saccharomyces cerevisiae mutants with altered trehalose 6-phosphate dynamics. Biochem. J. 2013, 454, 227-233. [CrossRef] [PubMed]

43. Gancedo, C.; Flores, C.L. The importance of a functional trehalose biosynthetic pathway for the life of yeasts and fungi. FEMS Yeast Res. 2004, 4, 351-359. [CrossRef]

44. Conlin, L.K.; Nelson, H.C. The natural osmolyte trehalose is a positive regulator of the heat-induced activity of yeast heat shock transcription factor. Mol. Cell. Biol. 2007, 27, 1505-1515. [CrossRef]

45. Sekova, V.Y.; Gessler, N.N.; Isakova, E.P.; Antipov, A.N.; Dergacheva, D.I.; Deryabina, Y.I.; Trubnikova, E.V. Redox status of extremophilic yeast Yarrowia lipolytica during adaptation to $\mathrm{pH}$-stress. Prikl. Biokhim. Mikrobiol. 2015, 51, 570-577. [CrossRef] 
46. Koganti, S.; Kuo, T.M.; Kurtzman, C.P.; Smith, N.; Ju, L.K. Production of arabitol from glycerol: Strain screening and study of factors affecting production yield. Appl. Microbiol. Biotechnol. 2011, 90, 257-267. [CrossRef]

47. Toyoda, T.; Ohtaguchi, K. Effect of temperature on D-arabitol production from lactose by Kluyveromyces lactis. J. Ind. Microbiol. Biotechnol. 2011, 38, 1179-1185. [CrossRef]

48. Kieliszek, M.; Błażejak, S.; Bzducha-Wróbel, A.; Kot, A.M. Effect of selenium on growth and antioxidative system of yeast cells. Mol. Biol. Rep. 2019, 46, 1797-1808. [CrossRef]

49. Gientka, I.; Gadaszewska, M.; Błażejak, S.; Kieliszek, M.; Bzducha-Wróbel, A.; Stasiak-Różańska, L.; Kot, A.M. Evaluation of lipid biosynthesis ability by Rhodotorula and Sporobolomyces strains in medium with glycerol. Eur. Food Res. Technol. 2017, 243, 275-286. [CrossRef]

50. Kot, A.M.; Błażejak, S.; Kieliszek, M.; Gientka, I.; Bryś, J. Simultaneous Production of Lipids and Carotenoids by the Red Yeast Rhodotorula from Waste Glycerol Fraction and Potato Wastewater. Appl. Biochem. Biotechnol. 2019, 189, 589-607. [CrossRef]

51. Mattanna, P.; Dallé da Rosa, P.; Gusso, A.P.; Richards, N.S.; Valente, P. Enhancement of microbial oil production by alpha-linolenic acid producing Yarrowia lipolytica strains QU22 and QU137. Food Sci. Biotechnol. 2014, 23, 1929-1934. [CrossRef]

52. Pascual-Ahuir, A.; Manzanares-Estreder, S.; Timón-Gómez, A.; Proft, M. Ask yeast how to burn your fats: Lessons learned from the metabolic adaptation to salt stress. Curr. Genet. 2017, 64, 63-69. [CrossRef] [PubMed]

53. Haines, T.H.; Dencher, N.A. Cardiolipin: A proton trap for oxidative phosphorylation. FEBS Lett. 2002, 528, 35-39. [CrossRef]

54. Joshi, A.S.; Zhou, J.; Gohil, V.M.; Chen, S.; Greenberg, M.L. Cellular functions of cardiolipin in yeast. Biochim. Biophys. Acta 2009, 1793, 212-218. [CrossRef]

55. Rostovtseva, T.K.; Gurnev, P.A.; Chen, M.; Bezrukov, S.M. Membrane lipid composition regulates tubulin interaction with mitochondrial voltage-dependent anion channel. J. Biol. Chem. 2012, 287, 29589-29598. [CrossRef]

56. Glatz, A.; Pilbat, A.M.; Németh, G.L.; Vince-Kontár, K.; Jósvay, K.; Hunya, Á.; Udvardy, A.; Gombos, I.; Péter, M.; Balogh, G.; et al. Involvement of small heat shock proteins, trehalose, and lipids in the thermal stress management in Schizosaccharomyces pombe. Cell Stress Chaperones 2016, 21, 327-333. [CrossRef]

57. McMaster, C.R. From yeast to humans-Roles of the Kennedy pathway for phosphatidylcholine synthesis. FEBS Lett. 2018, 592, 1256-1272. [CrossRef]

58. Niu, L.; Nomura, K.; Iwahashi, H.; Matsuoka, H.; Kawachi, S.; Suzuki, Y.; Tamura, K. Petit-high pressure carbon dioxide stress increases synthesis of S-adenosylmethionine and phosphatidylcholine in yeast Saccharomyces cerevisiae. Biophys. Chem. 2017, 231, 79-86. [CrossRef]

59. Boumann, H.A.; Gubbens, J.; Koorengevel, M.C.; Oh, C.S.; Martin, C.E.; Heck, A.J.; Patton-Vogt, J.; Henry, S.A.; de Kruijff, B.; de Kroon, A.I. Depletion of phosphatidylcholine in yeast induces shortening and increased saturation of the lipid acyl chains: Evidence for regulation of intrinsic membrane curvature in a eukaryote. Mol. Biol. Cell 2006, 17, 1006-1017. [CrossRef]

60. Ianutsevich, E.A.; Danilova, O.A.; Groza, N.V.; Kotlova, E.R.; Tereshina, V.M. Heat shock response of thermophilic fungi: Membrane lipids and soluble carbohydrates under elevated temperatures. Microbiology 2016, 162, 989-999. [CrossRef]

61. Klose, C.; Tarasov, K. Profiling of Yeast Lipids by Shotgun Lipidomics. Methods Mol. Biol. 2016, 1361, $309-324$. [CrossRef] [PubMed]

62. Arinbasarova, A.Y.; Biryukova, E.N.; Medentsev, A.G. Antistress systems of the yeast Yarrowia lipolitica. Prikl. Biokhim. Mikrobiol. 2015, 51, 122-131. [CrossRef]

63. Epova, E.Y.; Balovneva, M.V.; Isakova, E.P.; Kudykina, Y.K.; Zylkova, M.V.; Deryabina, Y.I.; Shevelev, A.B. Expression System for Yarrowia lipolytica Based on a Promoter of the Mitochondrial Potential-dependent Porin VDAC Gene. Biotechnol. Bioprocess Eng. 2016, 21, 408-413. [CrossRef]

64. Kwolek-Mirek, M.; Zadrag-Tecza, R. Comparison of methods used for assessing the viability and vitality of yeast cells. FEMS Yeast Res. 2014, 14, 1068-1079. [CrossRef] [PubMed]

65. Deryabina, Y.; Isakova, E.; Antipov, A.; Saris, N.-E.L. The inhibitors of antioxidant cell enzymes induce permeability transition in yeast mitochondria. J. Bioenerg. Biomembr. 2013, 45, 491-504. [CrossRef] [PubMed] 
66. Deryabina, Y.; Isakova, E.; Sekova, V.; Antipov, A.; Saris, N.-E.L. Inhibition of free radical scavenging enzymes affects mitochondrial membrane permeability transition during growth and aging of yeast cells. J. Bioenerg. Biomembr. 2014, 46, 479-492. [CrossRef]

67. Nichols, B.W. Separation of the lipids of photosynthetic tissues: Improvements in analysis by thin-layer chromatography. Biochim. Biophys. Acta 1963, 70, 417-422. [CrossRef]

68. Kates, M. Techniques of Lipidology: Isolation, Analysis, and Identification of Lipids, 2nd ed.; Elsevier: Amsterdam, The Netherlands, 1986; p. 464.

69. Benning, C.; Huang, Z.H.; Gage, D.A. Accumulation of a novel glycolipid and a betaine lipid in cells of Rhodobacter sphaeroides grown under phosphate limitation. Arch. Biochem. Biophys. 1995, 317, 103-111. [CrossRef]

70. Somogyi, M. Determination of blood sugar. J. Biol. Chem. 1945, 160, 69-73.

71. Brobst, K.M.; Tai, H. Determination of chlorohydrins in hydroxypropyl starch ethers. J. Assoc. Anal. Chem. 1971, 54, 1093-1094.

(C) 2019 by the authors. Licensee MDPI, Basel, Switzerland. This article is an open access article distributed under the terms and conditions of the Creative Commons Attribution (CC BY) license (http://creativecommons.org/licenses/by/4.0/). 